\title{
Malabaricone C Attenuates Nonsteroidal Anti-Inflammatory Drug-Induced Gastric Ulceration by Decreasing Oxidative/Nitrative Stress and Inflammation and Promoting Angiogenic Autohealing
}

\author{
Madhuri Basak,, ${ }^{1, *}$ Tarun Mahata,, ${ }^{1, *}$ Sreemoyee Chakraborti, ${ }^{1}$ Pranesh Kumar, ${ }^{2}$ Bolay Bhattacharya, ${ }^{3}$ \\ Sandip Kumar Bandyopadhyay, ${ }^{4}$ Madhusudan Das, ${ }^{5}$ Adele Stewart, ${ }^{6}$ Sudipta Saha, ${ }^{2}$ and Biswanath Maity ${ }^{1}$
}

\begin{abstract}
Aims: Nonsteroidal anti-inflammatory drugs (NSAIDs), among the most commonly used drugs worldwide, are associated with gastrointestinal (GI) complications that severely limit the clinical utility of this essential class of pain medications. Here, we mechanistically dissect the protective impact of a natural product, malabaricone $\mathrm{C}$ (Mal C), on NSAID-induced gastropathy.

Results: Mal C dose dependently diminished erosion of the stomach lining and inflammation in mice treated with NSAIDs with the protective impact translating to improvement in survival. By decreasing oxidative and nitrative stress, Mal C treatment prevented NSAID-induced mitochondrial dysfunction and cell death; nuclear factor $\kappa$-light-chain enhancer of activated B cell induction, release of proinflammatory cytokines and neutrophil infiltration; and disruptions in the vascular endothelial growth factor/endostatin balance that contributes to mucosal autohealing. Importantly, Mal $\mathrm{C}$ failed to impact the therapeutic anti-inflammatory properties of multiple NSAIDs in a model of acute inflammation. In all assays tested, Mal $\mathrm{C}$ proved as or more efficacious than the current first-line therapy for NSAID-dependent GI complications, the proton pump inhibitor omeprazole.

Innovation: Given that omeprazole-mediated prophylaxis is, itself, associated with a shift in NSAID-driven GI complications from the upper GI to the lower GI system, there is a clear and present need for novel therapeutics aimed at ameliorating NSAID-induced gastropathy. Mal C provided significant protection against NSAID-induced gastric ulcerations impacting multiple critical signaling cascades contributing to inflammation, cell loss, extracellular matrix degradation, and angiogenic autohealing.

Conclusion: Thus, Mal C represents a viable lead compound for the development of novel gastroprotective agents. Antioxid. Redox Signal. 32, 766-784.
\end{abstract}

Keywords: NSAID, gastric ulcer, antioxidant, inflammation, angiogenesis

${ }^{1}$ Centre of Biomedical Research, Sanjay Gandhi Post-Graduate Institute of Medical Sciences Campus, Lucknow, India.

${ }^{2}$ Department of Pharmaceutical Sciences, Babasaheb Bhimrao Ambedkar University, Lucknow, India.

${ }^{3}$ Department of Pharmacy, Geethanjali College of Pharmacy, Cheeryala, India.

${ }_{5}^{4}$ Department of Biochemistry, KPC Medical College and Hospital, Kolkata, India.

${ }^{5}$ Department of Zoology, University of Calcutta, Kolkata, India.

${ }^{6}$ Department of Biomedical Science, Charles E. Schmidt College of Medicine, Florida Atlantic University, Jupiter, Florida.

*These two authors contributed equally. 


\section{Innovation}

The current first-line treatment for nonsteroidal antiinflammatory drug (NSAID)-induced gastrointestinal adverse events is the proton pump inhibitor (PPI) omeprazole. However, PPI-based prophylaxis is, itself, associated with severe side effects. Given the widespread use of NSAIDs in pain management globally, there is a clear and pressing need for a new standard of care, necessitating a search for novel gastroprotective molecules. Here we identify the natural product malabaricone $\mathrm{C}$ (Mal C) as a multifunctional blocker of NSAID-induced gastric ulceration. Thus, Mal C represents a viable new lead compound for the development of novel therapeutics aimed at treating or preventing NSAID-induced ulcers.

\section{Introduction}

$\mathbf{N}$ ONSTEROIDAL ANTI-INFLAMMATORY DRUGS (NSAIDs), available via prescription and over the counter, are among the most commonly used drugs worldwide with 70 million prescriptions filled in the United States in 2017. By inhibiting the activity of cyclooxygenase (COX) enzymes, NSAIDs decrease the production of prostaglandins and thromboxanes ameliorating inflammation and blood clotting, respectively. Despite their ubiquitous availability and use, chronic NSAID consumption is associated with a number of adverse effects, including formation and delayed healing of gastroduodenal ulcers, as well as gastric bleeding and perforation $(35,47)$.

NSAID-dependent gastrointestinal (GI) complications are common, occurring in 1-2\% of users (51) and represent a large financial burden on the health care system (43). A1though concomitant therapy with agents aimed at decreasing gastric acidity such as the proton pump inhibitor (PPI) omeprazole can significantly mitigate NSAIDinduced GI injury $(19,45)$, recent evidence has linked PPI use to dysbiosis, alterations of the intestinal microbiota leading to low-grade, chronic inflammation $(21,33,61)$. Thus, there is a clear and present need for alternate strategies to prevent and treat GI complications resulting from prolonged NSAID use.

Formation of gastric ulcers following exposure to NSAIDs is believed to derive from inhibition of COX enzymes responsible for synthesis of cytoprotective prostaglandins in the gastric mucosa (60). Following injury, the GI epithelium possesses a remarkable capacity to autoheal, although prolonged NSAID exposure is known to interfere with this process. First, NSAIDs that reach the mitochondria have been shown to uncouple oxidative phosphorylation triggering opening of the mitochondrial transition pore, cytochrome $c$ release, and activation of proapoptotic caspases $(38,50)$.

At the same time, this mitochondrial dysfunction will lead to accumulation of cytosolic reactive oxygen species (ROS), further exacerbating cell loss and increasing permeability of the GI epithelium. Breakage of the intestinal barrier leads to the release of luminal factors that promote inflammation and neutrophil infiltration, further exacerbating mucosal damage (59). Ulcer healing requires proliferation and migration of epithelial cells into the compromised tissue, formation of granulation tissue, and neovascularization. A number of growth factors are known to drive these processes, including epidermal growth factor (EGF) (9), which promotes reepithelialization, and vascular endothelial growth factor (VEGF) (58), which stimulates restoration of connective tissue and the vasculature. NSAIDs are believed to delay repair by inhibiting synthesis of prostaglandin E2 $\left(\mathrm{PGE}_{2}\right)$ necessary for growth factor production in the ulcer margins.

We previously reported that malabaricone $\mathrm{C}$ (Mal C), a phenolic diarylnonanoid isolated from the rind of the plant Myristica malabarica (known as rampatri, Bombay mace, or false nutmeg), Myristica fragrans (Indonesian evergreen tree) (10), or Myristica cinnamomea (41), promotes healing following indomethacin-mediated acute ulceration $(3,4)$. In vitro, Mal $\mathrm{C}$ functions as an antioxidant and can efficiently scavenge hydroxyl radicals and chelate transition metals preventing free radical-induced lipid peroxidation (42). Similarly, Mal C coadministration decreased gastric protein oxidation and lipid peroxidation following acute indomethacin exposure in mice, with efficacy comparable with omeprazole (3). Where the mechanism of Mal C diverges from PPIs is in its ability to increase the levels of the proliferative and proangiogenic factors EGF and VEGF, respectively $(3,4)$, known to accelerate gastroduodenal ulcer healing $(9,30)$.

Mal $\mathrm{C}$ also possess potent anti-inflammatory actions improving the ratio of pro- to anti-inflammatory cytokines and suppressing activation of nuclear factor $\kappa$-light-chain enhancer of activated $\mathrm{B}$ cells $(\mathrm{NF}-\kappa \mathrm{B})$, following exposure of murine macrophages to the bacterial mimetic lipopolysaccharide $(23,31)$. These disparate observations suggest that Mal C may protect against NSAID-induced gastric ulceration via a combined ability to decrease oxidative stress, prevent inflammatory signaling, and maintain the autohealing capacity of GI tissues. Any or all of these mechanisms could contribute to the protective actions of Mal C in NSAIDinduced GI ulceration, but their singular or combined participation is yet to be investigated. The ultimate goal of this work was to provide a unifying model delineating the mechanism(s) by which Mal C ameliorates NSAID-induced GI damage.

\section{Results}

\section{Pharmacokinetic profile of Mal $C$ in mice}

Although Mal C (Fig. 1A) has been administered successfully to mice in prior studies without detectable impacts on animal health or behavior $(3,4)$, pharmacokinetic parameters for the drug are yet to be determined. We now report that $\mathrm{Mal} \mathrm{C}$ is rapidly cleared following intravenous (i.v.) administration $\left(t_{1 / 2}=\sim 5 \mathrm{~min}\right)$ (Fig. 1B). In contrast, oral administration results in sustainable Mal $\mathrm{C}$ levels over an hour (Fig. 1C). However, the maximal plasma levels achieved are several orders of magnitude lower compared with i.v. administration despite administration of $20 \times$ the dose (200 mg/kg, per os [p.o.]). Nevertheless, Mal C is detectable in the circulation following oral dosing.

\section{Mal C protects against indomethacin-induced gastric ulceration}

Mal C ameliorates acute NSAID-induced gastric ulceration in vivo $(3,4)$; however, the underlying mechanism(s) are yet to be elucidated. Mal $\mathrm{C}$ dose dependently improved the 

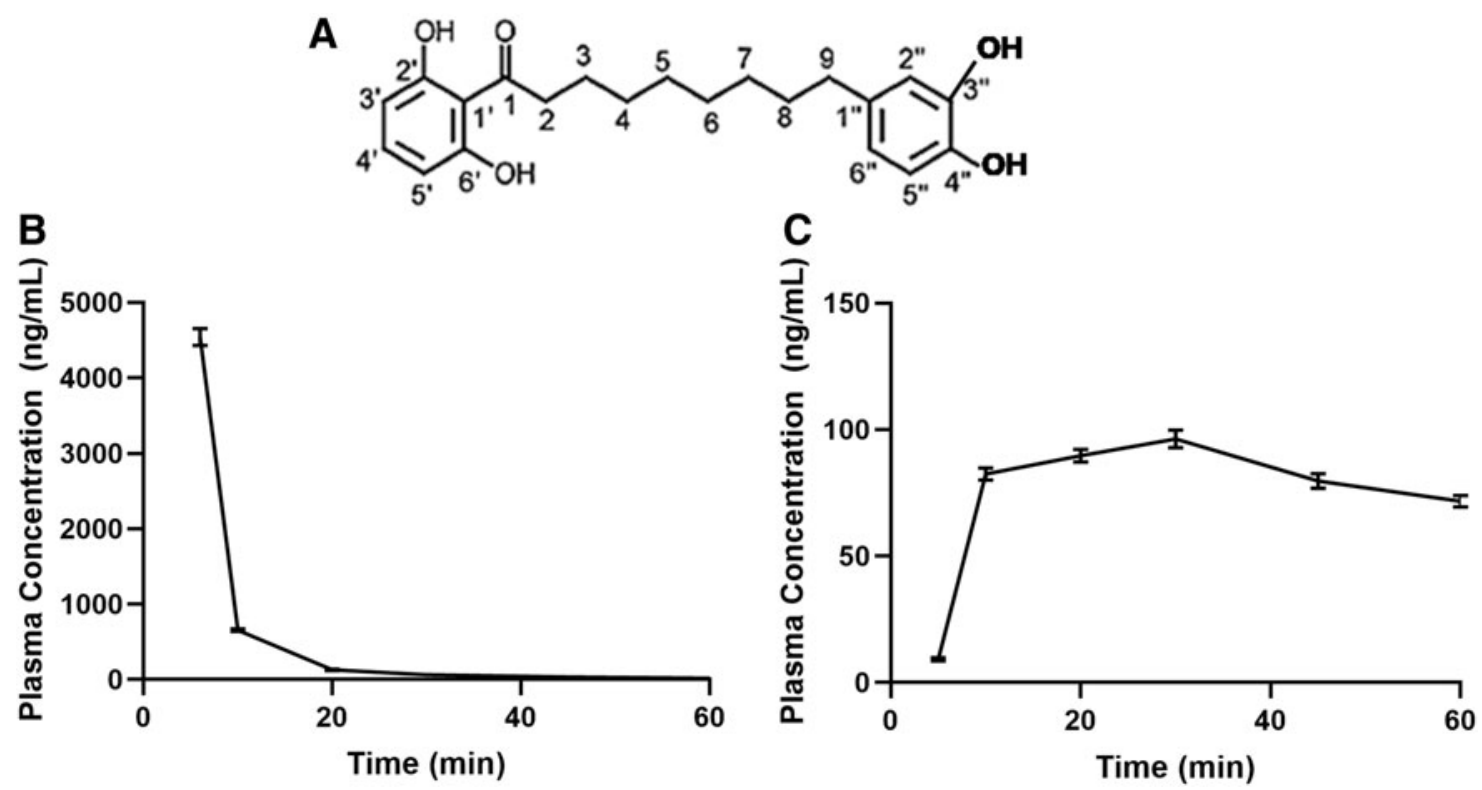

FIG. 1. Mal C plasma concentration over time following i.v. or oral administration. (A) Chemical structure of Mal C. Mice $(n=10)$ were given a single Mal C dose (B) intravenously $(10 \mathrm{mg} / \mathrm{kg}$, i.v.) or $(\mathbf{C})$ orally $(200 \mathrm{mg} / \mathrm{kg}$, p.o.), and plasma concentrations of Mal C determined by high-performance liquid chromatography 5-60 min following drug administration. Data are presented as mean \pm SEM. i.v., intravenous; Mal C, malabaricone C; p.o., per os; SEM, standard error of the mean.

histopathological appearance of indomethacin-induced mucosal lesions (Fig. 2A) and gastric inflammation (Fig. 2B). The largest impact of drug was seen on day 3 where indomethacin-treated animals displayed multiple ulceration patches with inflammatory infiltrate in the mucosa, submucosa, and muscle coat along with hemorrhagic serosa, while mice receiving Mal $\mathrm{C}$ displayed a significant decrease in inflammatory burden (Fig. 2A). As Mal C failed to provide further improvement in pathological endpoints over a dose of $10 \mathrm{mg} / \mathrm{kg}$, this dose was chosen for further study. At this optimized dose, the ability of Mal C to promote healing of gastric lesions following indomethacin exposure was accompanied by diminution in gastric juice acidity comparable with the PPI omeprazole (Fig. 2C) and improved animal survival (Fig. 2D). In addition to decreasing NSAIDdependent gastric ulceration to a greater extent than omeprazole, Mal $\mathrm{C}$ also proved more potent than other naturally occurring antioxidants, including vitamin $\mathrm{E}$ and curcumin, as well as synthetic antioxidants desferrioxamine and dimethyl sulfoxide (Fig. 2E).

\section{Mal $C$ attenuates indomethacin-induced, oxidative and nitrative stress-driven cell death and inflammation}

Given that Mal $\mathrm{C}$ was first identified as an antioxidant and significant evidence for a critical role of oxidative and nitrative stress in the pathogenesis of indomethacin-induced gastropathy (32), we next sought to evaluate the impact of Mal C on ROS and reactive nitrogen species (RNS) generation in the stomach of indomethacin-treated mice (34). Indomethacin triggered increases in hydrogen peroxide $\left(\mathrm{H}_{2} \mathrm{O}_{2}\right)$ (Fig. 3A) and decreases in superoxide dismutase (SOD) activity (Fig. 3B) and reduced glutathione (Fig. 3C). Indomethacin also caused a robust induction of inducible nitric oxide synthase (iNOS) with a corresponding decrease in endothelial nitric oxide synthase (eNOS) in gastric tissue (Fig. 3E), actions indicative of pathogenic NOS induction. In addition, the ratio of nitrite/nitrate was decreased by indomethacin (Fig. 3D), and nitric oxide synthase (NOS) activity was upregulated by indomethacin in the stomach (Fig. 3F) and serum (Supplementary Fig. S1A). In the stomach, a corresponding decrease in arginase activity was detected (Fig. 3G), likely representing a shift away from arginine metabolism to the NO/iNOS pathway, but arginase activity increased in serum (Supplementary Fig. S1B). Importantly, Mal $\mathrm{C}$ provided remarkable protection against perturbations in ROS and RNS levels. Using the nonselective dye 5-(and6)-chloromethyl-2', $7^{\prime}$-dichlorodihydrofluorescein diacetate (CM- $\mathrm{H}_{2}$ DCFDA) (22), we demonstrated that Mal C as well as the glutathione precursor $N$-acetylcysteine (NAC) or the specific inhibitor of iNOS N6-(1-iminoethyl)-L-lysine, dihydrochloride (L-NIL) lessened CM- $\mathrm{H}_{2}$ DCFDA fluorescence in gastric lysates from indomethacin-treated mice with Mal $\mathrm{C}$, providing no additional benefit to singular addition of the other two compounds (Fig. 2G).

NSAIDs uncouple mitochondrial oxidative phosphorylation leading to dissipation of the mitochondrial transmembrane potential (MTP), which, in addition to triggering the release of ROS such as superoxide and $\mathrm{H}_{2} \mathrm{O}_{2}$ into the cytosol, activates the caspase-dependent apoptotic pathway (32). We observed a dramatic loss of mitochondrial membrane potential $\left(\Delta \psi_{\mathrm{m}}\right)$ in tissues exposed to indomethacin that was restored by Mal C or NAC (Fig. 4A). No additive effects were observed for the combination treatment of Mal $\mathrm{C}$ and NAC. Mal C also prevented activation of initiator caspase-3 and executioner caspase-9 in gastric tissue lysates from indomethacin-treated mice (Fig. 4B, C). Impacts of Mal C on induction of the caspase cascade were mirrored via inhibition of iNOS, identifying pathogenic RNS as a driver of indomethacin-induced cell death (Fig. 4B, C). Indomethacin 
A

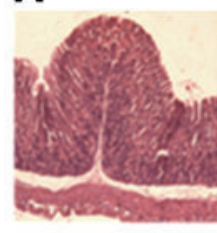

Control

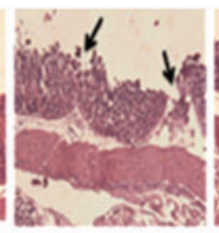

Ulcerated

untreated

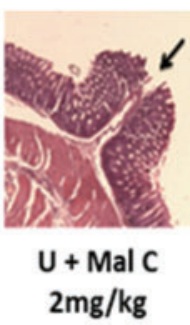

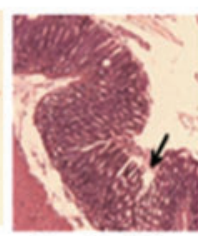

$\mathrm{U}+\mathrm{Mal} \mathrm{C}$ $5 \mathrm{mg} / \mathrm{kg}$

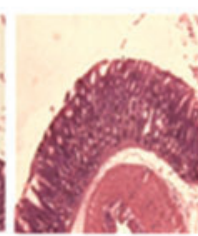

$\mathrm{U}+\mathrm{Mal} \mathrm{C}$ $10 \mathrm{mg} / \mathrm{kg}$

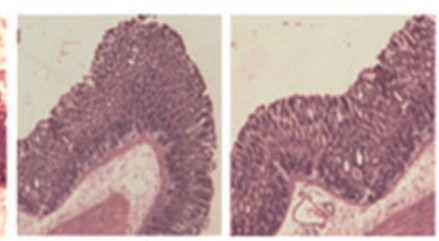

$\mathrm{U}+$ Mal C $20 \mathrm{mg} / \mathrm{kg}$

B

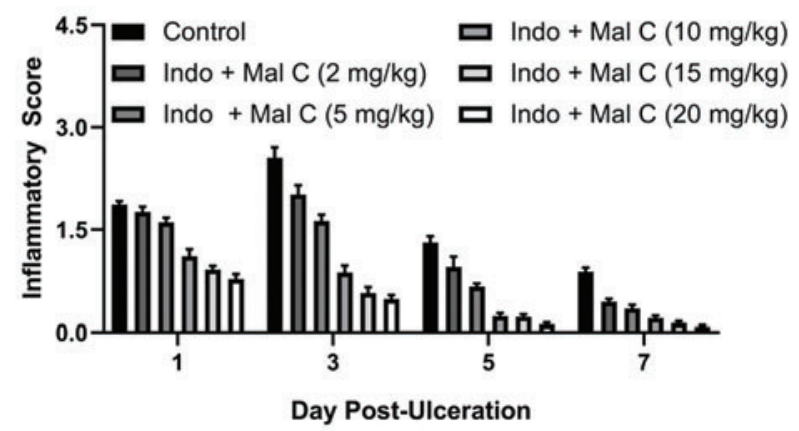

C
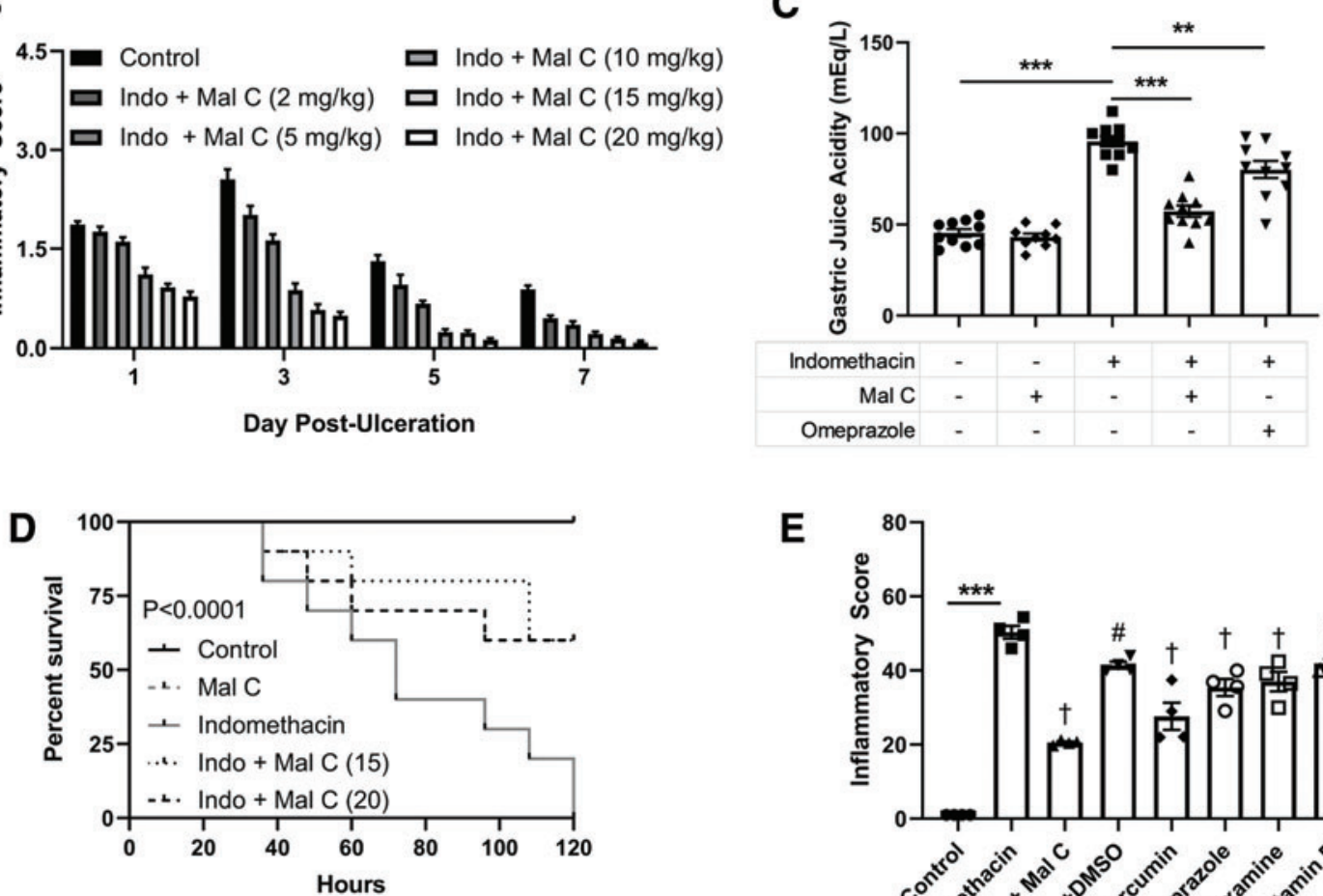

E

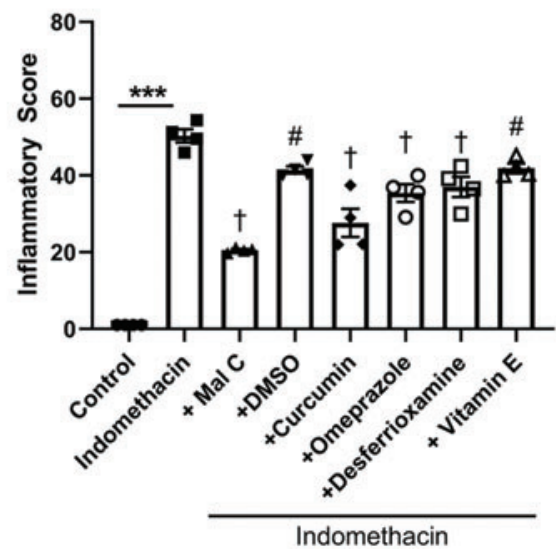

FIG. 2. Mal $\mathrm{C}$ decreases gastric inflammation following indomethacin exposure with improved efficacy over omeprazole. Stomach ulceration in mice was induced by oral administration of indomethacin $(18 \mathrm{mg} / \mathrm{kg}$, p.o.). Mal C was given at varying doses (5-20 mg/kg, p.o.) and monitored up to 7 days after indomethacin exposure. (A) Representative hematoxylin and eosin staining of gastric tissue of mice $(n=6)$. Black arrows indicate substantive endothelial erosion and ulceration 3 days following indomethacin exposure and improved dose dependently by Mal C. (B) Comparative dose-dependent healing capacity of Mal C against indomethacin-induced stomach ulceration in mice $(n=10)$ as revealed by histological inflammatory scores. (C) The ulcerated mice were treated with Mal C $(10 \mathrm{mg} / \mathrm{kg}$, p.o.) or omeprazole $(3 \mathrm{mg} / \mathrm{kg}$, p.o.) for 3 days. Gastric tissue homogenates $(n=10)$ were prepared to evaluate gastric juice acidity. (D) Survival rate was recorded $(n=10)$ throughout the treatment paradigm. $(\mathbf{E})$ Mice were treated with indomethacin in the presence or absence of various natural and synthetic antioxidants (DMSO- $1 \mathrm{~mL} / \mathrm{kg}$, i.p.; curcumin $-40 \mathrm{mg} / \mathrm{kg}$ i.p.; desferrioxamine- $800 \mathrm{mg} / \mathrm{kg}$, i.p.; vitamin E- $60 \mathrm{mg} / \mathrm{kg}$, i.p.; Mal C $-10 \mathrm{mg} / \mathrm{kg}$, p.o.; or omeprazole $-3 \mathrm{mg} / \mathrm{kg}$, p.o.) for 3 days. Gastric tissues $(n=4)$ were then harvested and inflammatory scores determined. $* * p<0.01$ and $* * * p<0.001$; ${ }^{\#} p<0.05$ and ${ }^{\dagger} p<0.001$ versus indomethacin-only treatment group. Data were analyzed by one- or two-way ANOVA with post hoc tests where appropriate. Kaplan-Meier survival curves were analyzed using the log-rank (Mantel-Cox) test. Data are presented as mean \pm SEM. ANOVA, analysis of variance; DMSO, dimethyl sulfoxide. Color images are available online.

directly triggers apoptosis in isolated gastrointestinal epithelial cell (GEC), an effect ameliorated by NAC and Mal C (Supplementary Fig. S2C). Indeed, the ability of Mal C, NAC, and L-NIL, alone or in combination, to prevent caspase activation in GECs was comparable, suggesting that, at the cellular level, Mal C, NAC, and L-NIL target over- lapping pathway(s) in indomethacin-induced apoptosis (Supplementary Fig. S2A, B). To provide additional insight into source(s) of ROS/RNS critical for indomethacinmediated GEC loss, cells were exposed to scavengers of superoxide (polyethylene glycol-superoxide dismutase [Peg-SOD]), $\mathrm{H}_{2} \mathrm{O}_{2}$ (polyethylene glycol-catalase [Peg-Cat]), 
A

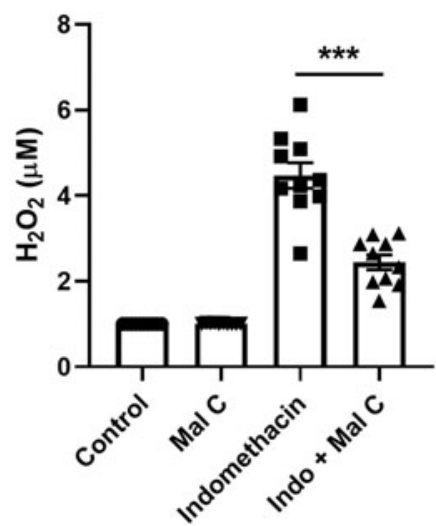

$B$

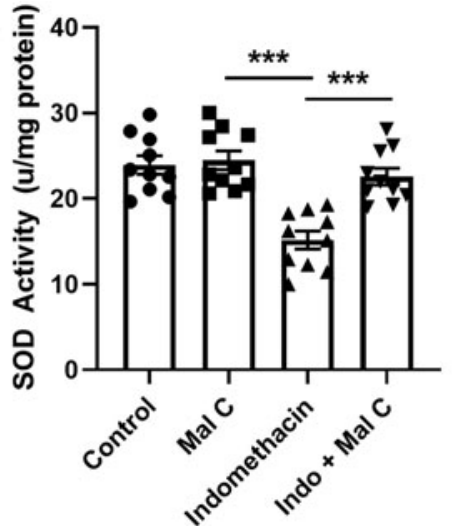

C

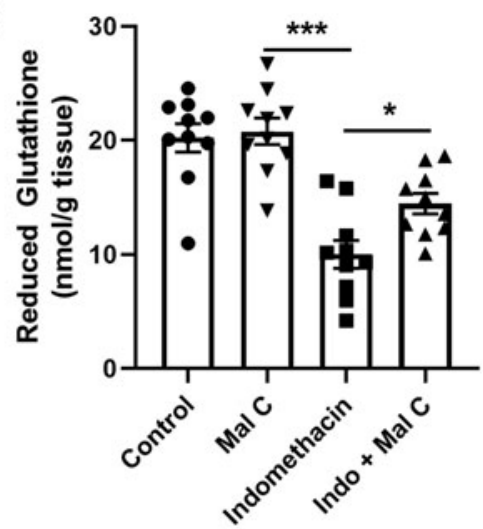

D
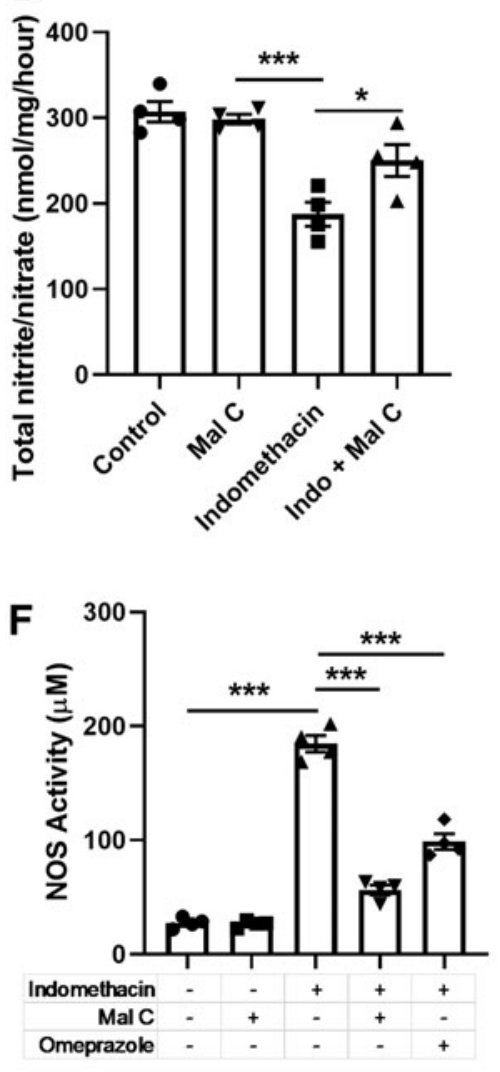

$\mathbf{E}$
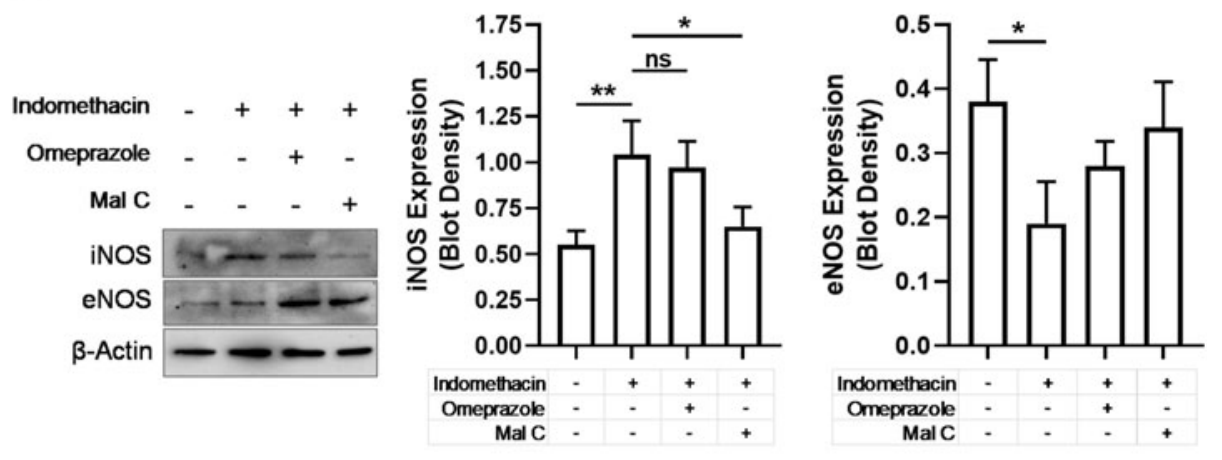

FIG. 3. Mal C protects against oxidative stress induced by indomethacin in the stomach. Mice were treated with indomethacin $(18 \mathrm{mg} / \mathrm{kg}$, p.o.) with or without Mal C $(10 \mathrm{mg} / \mathrm{kg}$, p.o.) or omeprazole $(3 \mathrm{mg} / \mathrm{kg}$, p.o.) once per day upto 3 days. Control groups received vehicle or Mal $\mathrm{C}$ only. On day 3 postinjection, gastric tissue was harvested for analysis of (A) $\mathrm{H}_{2} \mathrm{O}_{2}$ levels $(n=10)$, (B) SOD activity $(n=10),($ C) reduced glutathione activity $(n=10)$, and (D) total nitrite/nitrate content $(n=4)$. Gastric tissue was collected to measure (E) expression of eNOS and iNOS $(n=3$, actin serves as a loading control), (F) NOS activity $(n=4)$, and (G) Arginase activity $(n=4)$ in gastric tissue lysates. (H) Isolated primary GECs were pretreated for $1 \mathrm{~h}$ with Mal C $(10 \mu M)$, the iNOS inhibitor L-NIL $(50 \mu M)$, or general ROS scavenger NAC $(5 \mathrm{~m} M)$, alone or in various combinations. Cells were then stressed with indomethacin $(30 \mu M)$ for $24 \mathrm{~h}$. Cellular lysates $(n=4)$ were used to measure ROS generation $\left(\mathrm{CM}-\mathrm{H}_{2}\right.$ DCFDA fluorescence). ${ }^{*} p<0.05$, $* * p<0.01$, and ${ }^{* * *} p<0.001$; ns, not significant. Data were analyzed by one-way ANOVA with Sidak's post hoc test. Data are presented as mean \pm SEM. bw, body weight; CM$\mathrm{H}_{2}$ DCFDA, 5-(and-6)-chloromethyl-2', $7^{\prime}$-dichlorodihydrofluorescein diacetate; eNOS, endothelial nitric oxide synthase; GEC, gastrointestinal epithelial cell; $\mathrm{H}_{2} \mathrm{O}_{2}$, hydrogen peroxide; iNOS, inducible nitric oxide synthase; L-NIL, N6-(1iminoethyl)-L-lysine, dihydrochloride; NAC, $N$-acetylcysteine; ROS, reactive oxygen species; SOD, superoxide dismutase. 

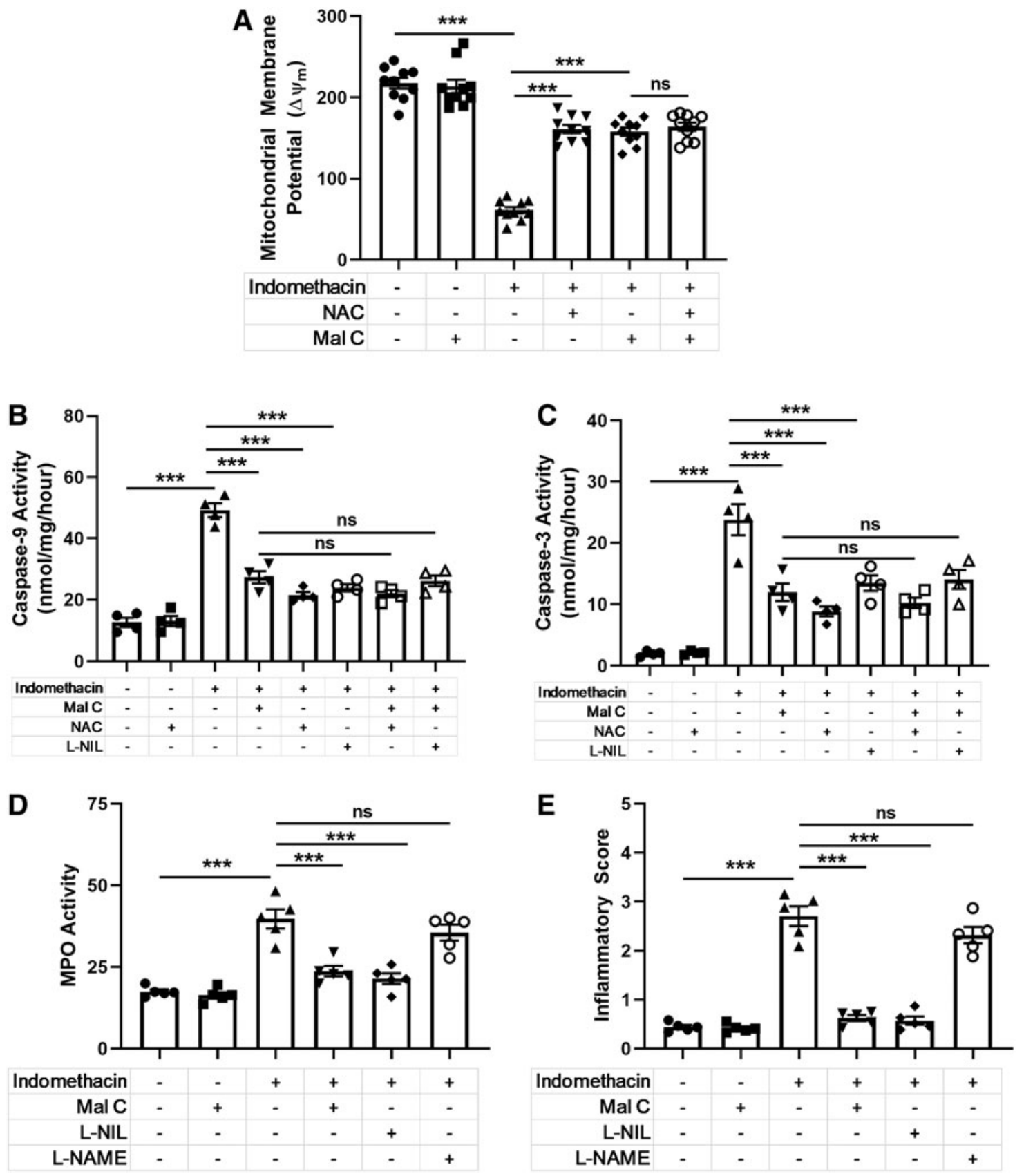

FIG. 4. Mal $\mathrm{C}$ ameliorates indomethacin-induced cell death and inflammation by decreasing oxidative and nitrative stress. Mice were treated with indomethacin $(18 \mathrm{mg} / \mathrm{kg}$ bw) alone or in the presence of Mal C (10 mg/kg, p.o.), ROS scavenger NAC ( $250 \mathrm{mg} / \mathrm{kg}$, once daily, p.o.), the selective iNOS inhibitor L-NIL (3 mg/kg, twice daily, p.o.), and/or the nonselective inhibitor of NOS L-NAME $(10 \mathrm{mg} / \mathrm{kg}$, once daily, p.o.) for 3 days. (A) Mitochondrial membrane potential $\left(\Delta \psi_{\mathrm{m}}\right)$ was detected in tissue homogenates $(n=10)$ by spectrofluorometry following addition of JC-1 dye. (B) Caspase-9 and (C) caspase-3 activity was measured from the cytosolic fraction of gastric mucosal homogenates $(n=10)$ obtained by subcellular fractionation. (D) MPO activity $(n=5)$ as a proxy for neutrophil infiltration and (E) inflammatory scores $(n=5)$ in stomach. $* * * p<0.001$; ns, not significant. Data were analyzed by one- or two-way ANOVA with Sidak's post hoc test. Data are presented as mean \pm SEM. L-NAME, $N(\mathrm{G})$-nitro-L-arginine methyl ester; MPO, myeloperoxidase.

or hydroxyl radicals (dimethylthiourea [DMTU]), or inhibitors of NOS $(N(\mathrm{G})$-nitro-L-arginine methyl ester [L-NAME]) or iNOS L-NIL). Inhibition of iNOS or superoxide $/ \mathrm{H}_{2} \mathrm{O}_{2}$ scavenging decreased GEC apoptosis following indomethacin treatment (Supplementary Fig. S2D), with Mal C providing no additive benefit. Thus, Mal C may prevent GEC death in response to indomethacin by ame- liorating oxidative and nitrative stress. Importantly, both Mal C and L-NIL, but not the nonselective NOS inhibitor L-NAME, reduced neutrophil infiltration (Fig. 4D) and overall inflammatory burden in indomethacin-treated stomachs (Fig. 4E), underscoring the importance of iNOS activity in key pathological endpoints induced by indomethacin in the gut. 


\section{Mal C decreases gastric inflammation following} indomethacin exposure

Excessive infiltration of activated neutrophils is a critical step in the formation of gastric ulcers $(5,6,53)$. The production of multiple proinflammatory mediators and adhesion molecules, controlled by the transcription factor NF- $\kappa \mathrm{B}$, at the site of injury triggers immune cell recruitment (29). In both tissue and serum from mice administered indomethacin and treated with GECs, Mal C prevented upregulation of the proinflammatory cytokines tumor necrosis factor- $\alpha$ (TNF- $\alpha)$, interleukin (IL)-1 $\beta$, and IL-6 (Fig. 5A and Supplementary S3A, C) and downregulation of anti-inflammatory cytokines IL-4, TGF- $\beta 1$, and IL-10 (Fig. 5B and Supplementary S3B, D). In keeping with NF- $\kappa$ B-driven activation of inflammatory cascades, NF- $\kappa \mathrm{B}$ was upregulated in stomachs isolated from indomethacin-exposed animals and decreased by Mal $\mathrm{C}$, but not omeprazole (Fig. 5C). In isolated GECs, indomethacin promoted nuclear accumulation of $\mathrm{NF}-\kappa \mathrm{B}$, actions blocked by NAC or Mal C (Supplementary Fig. S4A), suggesting that ROS drive NF- $\kappa \mathrm{B}$ activation. Indeed, in indomethacin-treated GECs, NAC or L-NIL, but not the NF- $\kappa$ B inhibitor Bay11, decreased ROS generation (Supplementary Fig. S4B), suggesting that NF- $\kappa \mathrm{B}$ functions downstream of ROS.

In addition to stimulation of cytokine production, NF- $\kappa \mathrm{B}$ signaling also drives upregulation of cell adhesion molecules and modulators of the extracellular matrix, including matrix metalloproteinase 9 (MMP-9), a protease implicated in a number of pathophysiological processes, including neutrophil migration and angiogenesis $(2,8,13,40)$. Indomethacin led to a robust upregulation of MMP-9 protein and activity (Fig. 5D) in gastric tissue. Unlike omeprazole, Mal C administration prevented indomethacin-induced MMP-9 activation and protein accumulation, while thalidomide, a nonspecific MMP inhibitor, decreased MMP-9 activity only (Fig. 5D). MMP-9 upregulation is dependent on NF- $\kappa \mathrm{B}$ activation as Bay11 decreased indomethacin-induced MMP-9 protein accumulation to the same degree as Mal C (Fig. 5E, F). Similar to data obtained for NF- $\kappa$ B activation (Supplementary Fig. S4A), NAC or Mal C had a larger impact than LNIL on indomethacin-dependent MMP-9 upregulation in GECs (Supplementary Fig. S4C), suggesting that ROS (not RNS) mediate NF- $\kappa$ B-driven MMP-9 activation. Consistent with MMP-9 data, we observed a corresponding decrease in tissue collagen content in indomethacin-treated mice rescued by Mal $\mathrm{C}$ administration (Fig. 5G).

\section{Mal $C$ promotes angiogenesis following indomethacin-induced gastric ulceration}

Angiogenic factors such as VEGF are critical for ulcer healing, and indomethacin has been shown to significantly impair this pathway $(20,57)$. Previous work has shown that Mal C treatment prevents indomethacin-induced VEGF suppression and elevations in the antiangiogenic factor endostatin (4), although the mechanism is yet to be elucidated. Indomethacin triggered downregulation in tissue VEGF content as well as expression of VEGF receptors Flk-1 and Flt-1 (Fig. 6A). A corresponding induction of endostatin was also observed. Remarkably, Mal $\mathrm{C}$ treatment prevented indomethacin's antiangiogenic actions leading to an increase in VEGF in tissue and serum (Fig. 6B and Supplementary Fig. S5A) and a decrease in endostatin (Fig. 6C and Sup- plementary Fig. S5B). Although VEGF expression often correlates with activity, VEGF bioavailability is also regulated extracellularly by MMPs (28). Indomethacin decreased MMP-2 expression in gastric tissue, the effect blocked by Mal C, but not omeprazole (Fig. 6D). Inhibition of MMP-2 or nonselective MMP inhibition (thalidomide) impaired the ability of Mal $\mathrm{C}$ to promote VEGF production following indomethacin treatment (Fig. 6E). Given that the impact of thalidomide and a selective MMP-2 blocker were similar when combined with Mal C, these data suggest that Mal C likely requires MMP-2 activity to counteract indomethacininduced VEGF downregulation.

\section{Mal $C$ fails to impact the anti-inflammatory actions of indomethacin}

Our data have consistently shown that Mal $\mathrm{C}$ protects against indomethacin-induced gastric ulceration to a greater degree than the current standard treatment, omeprazole. The therapeutic efficacy of NSAIDs relies on their ability to inhibit COX activity and the resultant prostaglandin synthesis, which maintain the mucosal lining. Indomethacin treatment decreased COX-1 and COX-2 expression in the stomach, effects reversed by Mal C (Fig. 7A). A corresponding decrease in $\mathrm{PGE}_{2}$ was observed following indomethacin exposure and rescued by Mal C (Fig. 7B). Thus, we were concerned that systemic administration of Mal $\mathrm{C}$ might interfere with the anti-inflammatory properties of indomethacin. To test this possibility, we utilized a well-characterized model of acute inflammation: carrageenan-induced paw edema. Carrageenan induced rapid paw swelling that could be alleviated by indomethacin (Fig. 7C). Importantly, Mal C failed to interfere with the beneficial impact of indomethacin in this assay (Fig. 7D).

\section{Mal $C$ protects against gastric damage, inflammation, and oxidative stress induced by naproxen and diclofenac}

Thus far, investigations into the impact of Mal $\mathrm{C}$ on NSAID-mediated gastric ulceration have been confined to the study of indomethacin. GI complications are shared side effects of multiple NSAIDs, including diclofenac and naproxen, and, as a result, we next sought to establish whether Mal C ameliorated gastric damage induced by other NSAIDs and if the contributing mechanism(s) were comparable with data obtained using indomethacin as an ulcerative agent. Indeed, Mal C improved the overall survival of diclofenac- and naproxen-exposed mice (Fig. 8A) with dose-dependent decreases in gastric lesion area (Fig. 8B). Similarly, Mal C provided significant protection against NSAID-induced gastric inflammation as measured by myeloperoxidase (MPO) activity (Fig. 8C) and overall inflammatory score (Fig. 8D). We also observed a decrease in ROS (Fig. 8E) and apoptotic indicators (Fig. 8F) in naproxen- or diclofenac-treated mice also given Mal C. These phenomena are likely driven, at least in part, by loss of endogenous antioxidant capacity as both drugs decreased SOD activity (Supplementary Fig. S6A) and reduced levels of glutathione (Supplementary Fig. S6B), effects reversed by Mal C. Finally, in keeping with results obtained with indomethacin, Mal $\mathrm{C}$ failed to interfere with the anti-inflammatory properties of either diclofenac or naproxen (Fig. 8G and Supplementary S6C) in carrageenan- 
A

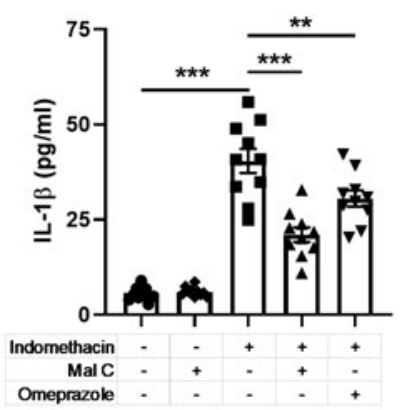

B

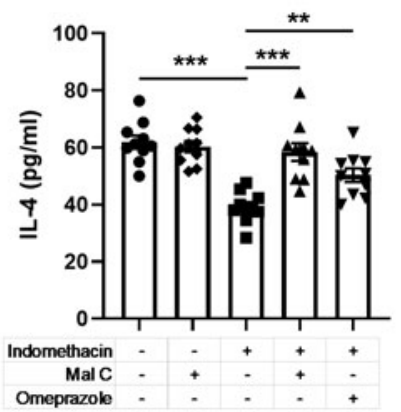

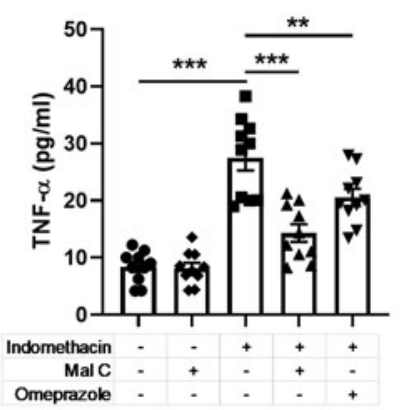

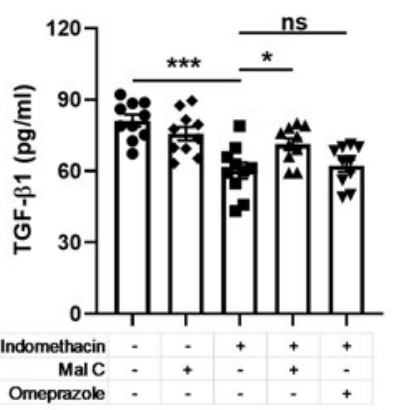

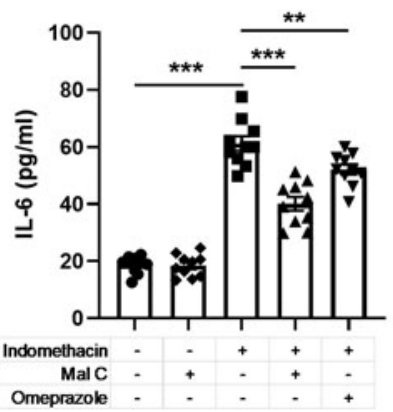

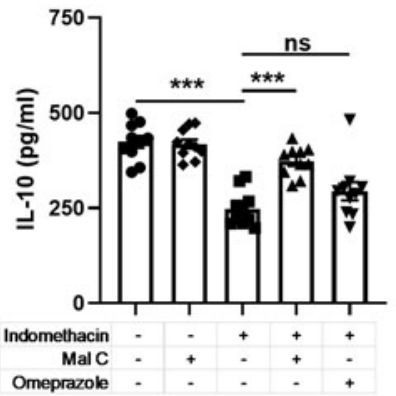

C

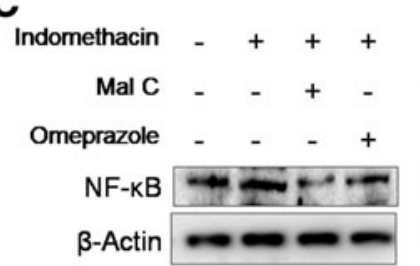

E

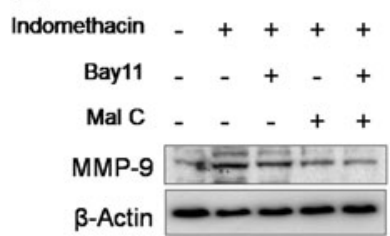

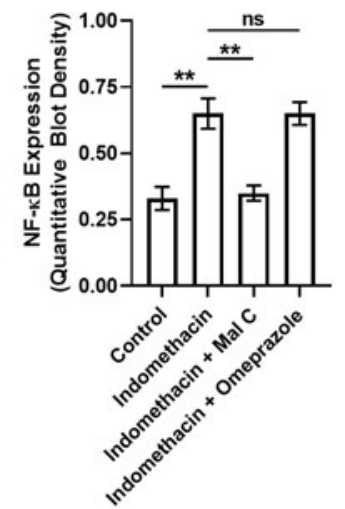

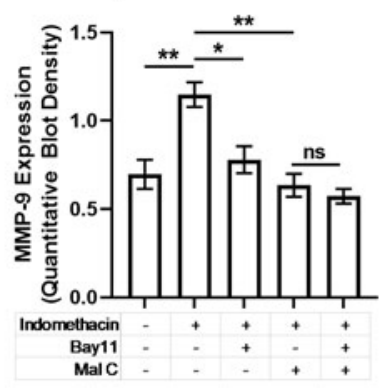

D
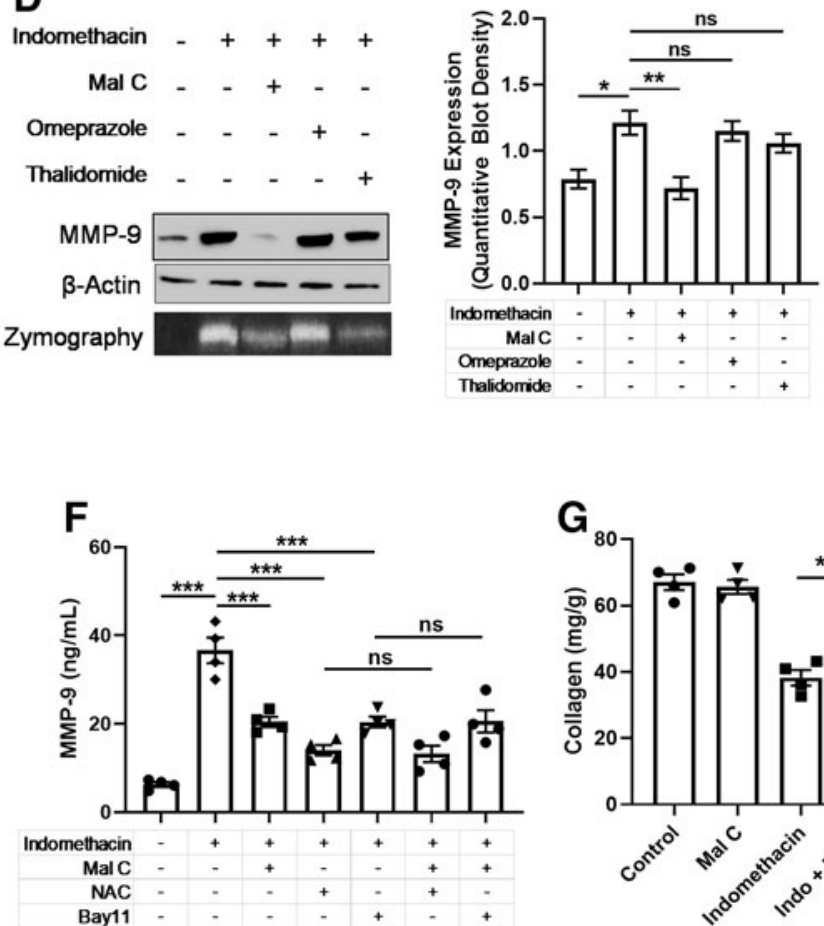

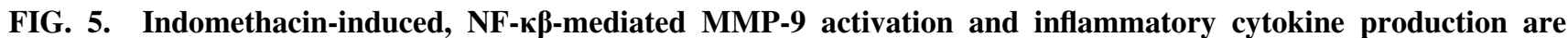
decreased by Mal C. Mice were treated with indomethacin $(18 \mathrm{mg} / \mathrm{kg}$, p.o.) with or without Mal C $(10 \mathrm{mg} / \mathrm{kg}$, p.o., once daily), omeprazole (3 $\mathrm{mg} / \mathrm{kg}$, p.o., once daily), Bay $11(5 \mathrm{mg} / \mathrm{kg}$, once daily, i.p.), and/or the nonspecific MMP inhibitor thalidomide $(200 \mathrm{mg} / \mathrm{kg}$, twice daily, i.p.) for 3 days. (A) Proinflammatory cytokines $(n=10)$ TNF- $\alpha$, IL-1 $\beta$, and IL-6 and (B) anti-inflammatory cytokine $(n=10)$ IL-4, TGF- $\beta 1$, and IL-10 levels were determined in gastric tissue lysates. (C) Immunoblotting was performed for NF- $\kappa \beta$ expression. Representative blot, as well as quantification from three independent experiments, is shown with $\beta$-actin as a loading control. (D) MMP-9 activation was determined via Western blotting (quantified from three independent experiments; $\beta$-actin serves as a loading control) or gelatin zymography in stomachs from mice treated with Mal C, omeprazole, or thalidomide following indomethacin exposure. (E) MMP-9 expression was determined via Western blotting $(n=3)$ or $(\mathbf{F})$ immunoassay $(n=4)$ in stomachs of indomethacin-treated mice given Mal C, NAC, or Bay 11 alone or in combination. $\beta$-Actin serves as a loading control. (G) Gastric tissue was processed and utilized for densitometric quantification of collagen content $(n=4)$. ${ }^{*} p<0.05$, ${ }^{* *} p<0.01$, and ${ }^{* * *} p<0.001$; ns, not significant. Data were analyzed by one-way ANOVA with Sidak's post hoc test. Data are presented as mean \pm SEM. IL, interleukin; MMP, matrix metalloproteinase; NF- $\kappa \mathrm{B}$, nuclear factor $\kappa$-light-chain enhancer of activated B cells; TGF- $\beta 1$, transforming growth factor- $\beta 1$; TNF- $\alpha$, tumor necrosis factor- $\alpha$. 

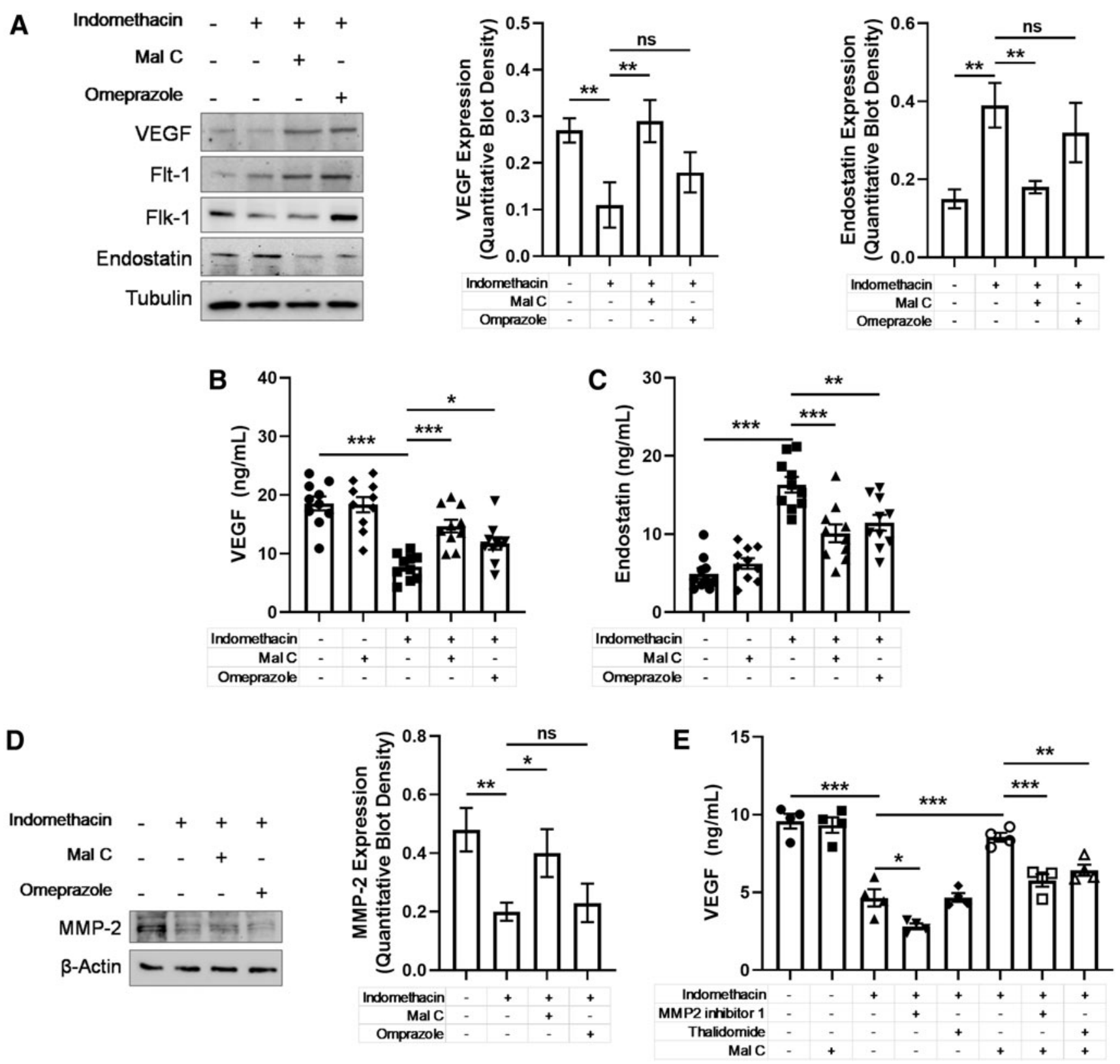

FIG. 6. Indomethacin-dependent increases in endostatin and decreases in VEGF levels are reversed by Mal C. Mice were treated with indomethacin $(18 \mathrm{mg} / \mathrm{kg}$. p.o.) alone and in combination with Mal C $(10 \mathrm{mg} / \mathrm{kg} \mathrm{p.o.)} \mathrm{or} \mathrm{omeprazole}(3 \mathrm{mg} / \mathrm{kg}$, p.o.) as a single dose per day. (A) Western blotting was performed on gastric tissue lysates ( $n=3$ /group) to measure protein expression of VEGF, Flk-1, Flt-1, and endostatin on day 3. VEGF and endostatin levels are quantified. Tubulin serves as a loading control. Gastric tissues $(n=10)$ were harvested for subsequent analyses of (B) VEGF and (C) endostatin levels via ELISA. (D) MMP-2 expression was determined in gastric tissue lysates and quantified $(n=3)$. $\beta$-Actin serves as a loading control. (E) Isolated primary GECs were pretreated for $1 \mathrm{~h}$ with the specific MMP-2 inhibitor, MMP2 inhibitor $1(5 \mu M)$, and MMP-9 inhibitor, thalidomide $(10 \mu \mathrm{g} / \mathrm{mL})$, in the presence or absence of Mal C $(10 \mu M)$, and cells were challenged with indomethacin for 36 h. $* p<0.05, * * p<0.01$, and $* * * p<0.001 ; \mathrm{ns}$, not significant. Data were analyzed by one-way ANOVA with Sidak's post hoc test. Data are presented as mean \pm SEM. ELISA, enzyme-linked immunosorbent assay; Flk-1, vascular endothelial growth factor receptor 2; Flt-1, vascular endothelial growth factor receptor 1; VEGF, vascular endothelial growth factor.

induced paw edema. These data show that Mal C might provide substantive protection against NSAID-dependent gastric ulceration for multiple NSAIDs.

\section{Discussion}

NSAIDs are among the most commonly used medications worldwide and represent critical alternatives to addictive opioid analgesics (11). Despite their widespread use, NSAIDs are associated with severe adverse effects, which include erosion of GI lining and gastric ulcer formation. Thus, chronic NSAID users are often provided prophylactic therapy aimed at neutralizing gastric acidity such as the PPI omeprazole $(19,45)$, which is associated with its own set of long-term side effects $(21,33,61)$. Here we explore the utility 

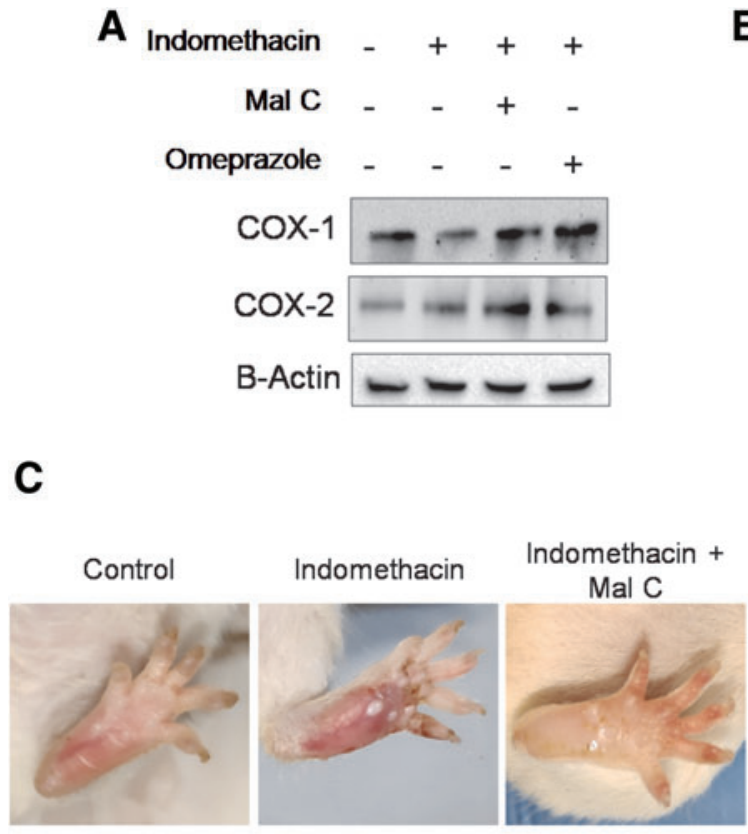
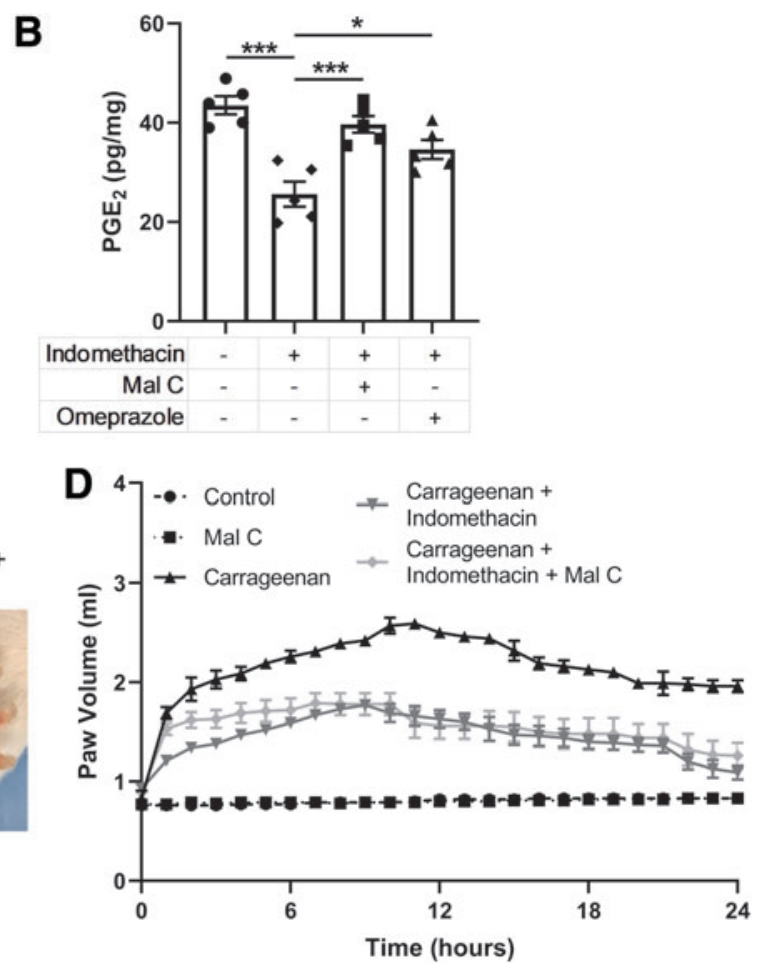

FIG. 7. Mal $\mathrm{C}$ improves stomach ulceration following indomethacin exposure without impacting the antiinflammatory properties of the drug. Gastric ulcers were induced in mice by indomethacin administration $(18 \mathrm{mg} / \mathrm{kg}$, p.o.). The ulcerated mice were treated with Mal C (10 mg/kg, p.o.) alone or in combination with omeprazole $(3 \mathrm{mg} / \mathrm{kg}$, p.o.) for 3 days. (A) Representative Western blots ( $n=3$ /group) probing for COX-1 and COX-2. For all Western blots, $\beta$-actin serves as a loading control. (B) Mucosal $\mathrm{PGE}_{2}$ levels were measured from gastric tissue homogenates $(n=5)$. In a separate study, paw edema was induced in mice $(n=4)$ by subplantar injection of carrageenan in the left hind foot pad. In a separate group, $1 \mathrm{~h}$ before carrageenan administration, animals received indomethacin $(5 \mathrm{mg} / \mathrm{kg}$, p.o.) alone or in combination with Mal C ( $2 \mathrm{mg} / \mathrm{kg}$, p.o.). (C) Representative images of typical peak paw swelling and (D) paw volume over time are depicted. ${ }^{*} p<0.05$ and $* * * p<0.001$. Data were analyzed by one-way ANOVA with Sidak's post hoc test. Data are presented as mean $\pm \mathrm{SEM}$. COX, cyclooxygenase; $\mathrm{PGE}_{2}$, prostaglandin E2. Color images are available online.

of a natural product, Mal C, in NSAID-induced gastric ulceration (Fig. 9). Mal C dose dependently improved the appearance of the gastric mucosa, gastric inflammation, gastric juice acidity, and overall animal survival. In investigating the mechanism of Mal $\mathrm{C}$ action in gastric damage resulting from chronic indomethacin exposure, we noted that the ability of Mal C to prevent oxidative and nitrative stress led to a corresponding diminution in mitochondrial dysfunction and cell death. Similarly, Mal C decreased NF- $\kappa$ B activation, the release of proinflammatory cytokines, activation of enzymes driving extracellular matrix remodeling such as MMP-9, and infiltration of neutrophils into the gastric endothelium. In addition to triggering GEC loss and gastric inflammation, continuing indomethacin exposure also impairs gastric autohealing by decreasing levels of the proangiogenic factor VEGF and its receptors and increasing levels of the antiangiogenic factor endostatin $(20,57)$. The addition of Mal C treatment led to almost complete rescue of the antiangiogenic actions of indomethacin.

The impacts of Mal $\mathrm{C}$ on oxidative and nitrative stress following NSAID treatment were widespread. Mal $\mathrm{C}$ effectively prevented elevations in SOD activity and $\mathrm{H}_{2} \mathrm{O}_{2}$ accumulation while simultaneously increasing reduced glutathione. Mitochondrial damage in addition to lipid, protein, and DNA oxidation resulting from indomethacin-mediated ROS generation triggers activation of apoptotic signaling and mucosal injury (54), a cascade of events blocked by Mal C. Similarly, Mal C prevented NSAID-induced upregulation of iNOS, downregulation of eNOS, changes in the nitrite/nitrate balance, and increases in NOS activity. L-arginine metabolized by arginase/NOS produces the free radical NO that plays an important role in mucosal defense (27). Disruptions in the eNOS/iNOS balance by indomethacin, in either GECs or infiltrating macrophages, compromise intestinal integrity, exacerbate inflammation, and delay healing. Scavenging of $\mathrm{H}_{2} \mathrm{O}_{2}$ or superoxide or inhibitors of iNOS protected against cell loss, with Mal C providing no added benefit, suggesting these agents target redundant mechanisms. However, due to the potential promiscuity of agents used for the studies described herein, further experimentation (e.g., cleaner, genetic approach) will be required to conclusively verify these assertions. At the cellular level, our data are consistent with an ROSdriven mechanism leading to proinflammatory NF- $\kappa \mathrm{B}$ activation and MMP-9 upregulation, effects that can be reversed by NAC or Mal C. In contrast, at the physiological level, iNOS inhibition had a profound impact on neutrophil infiltration and inflammatory burden in indomethacin- 

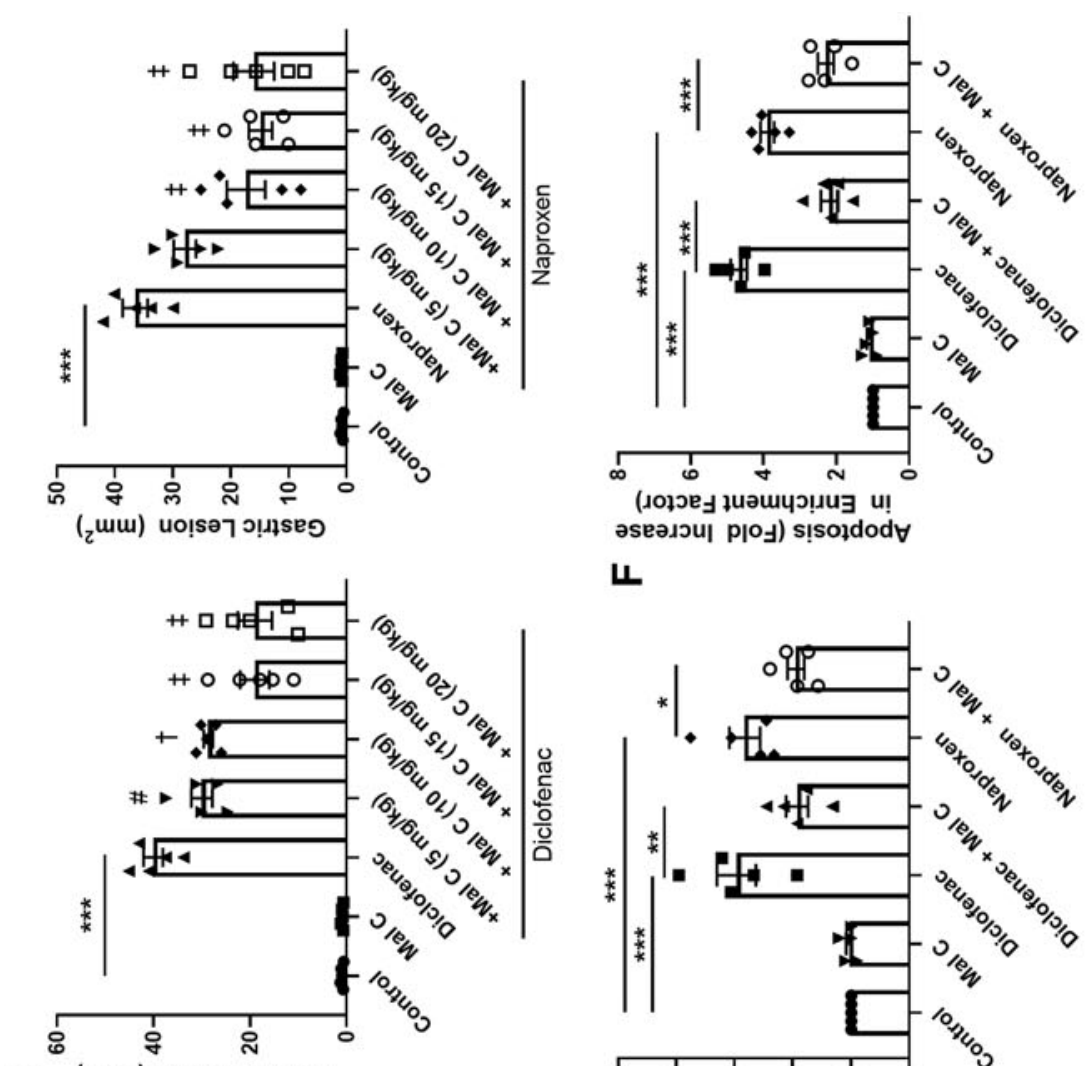

ᄂ

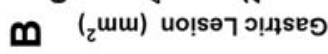
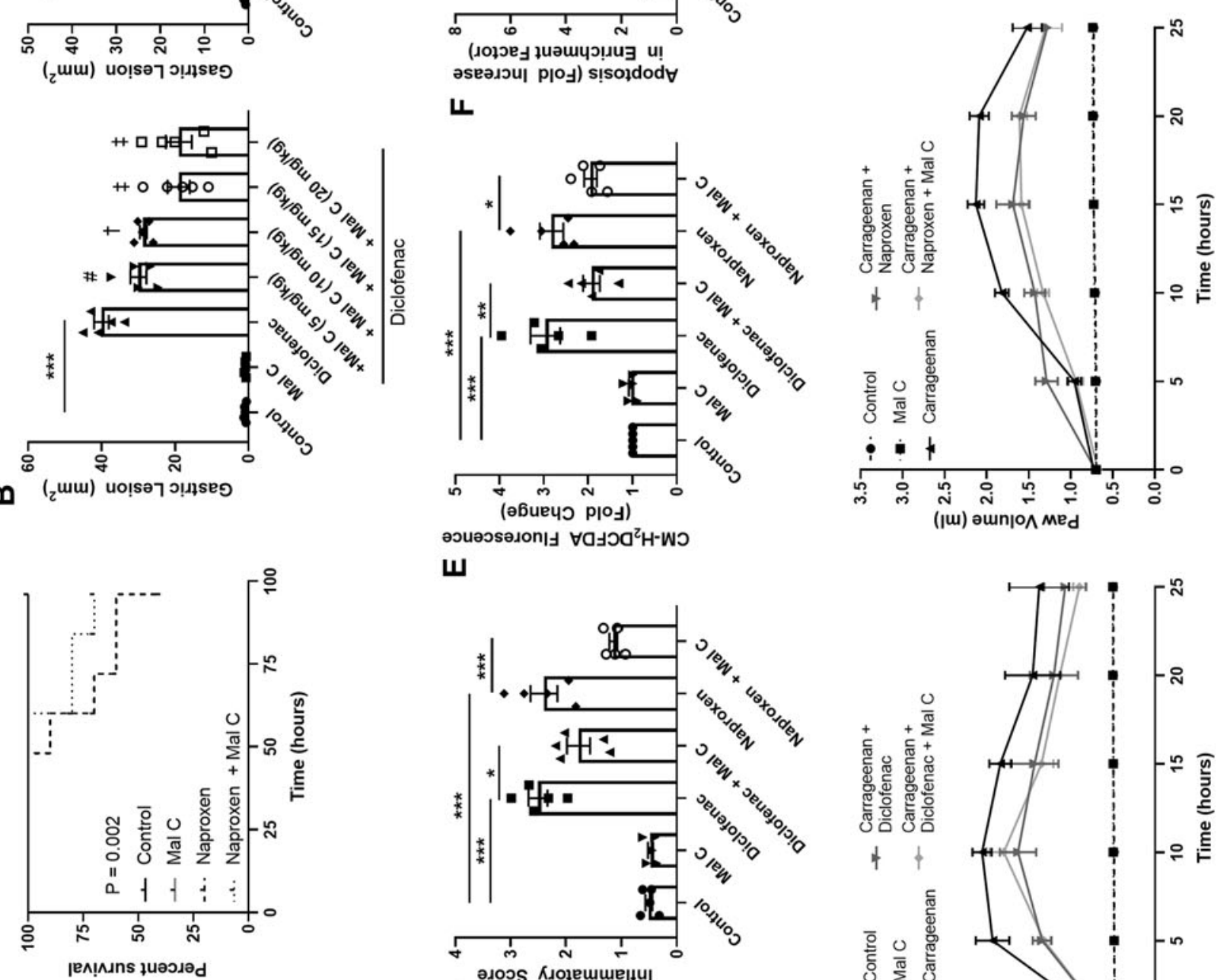

Ш
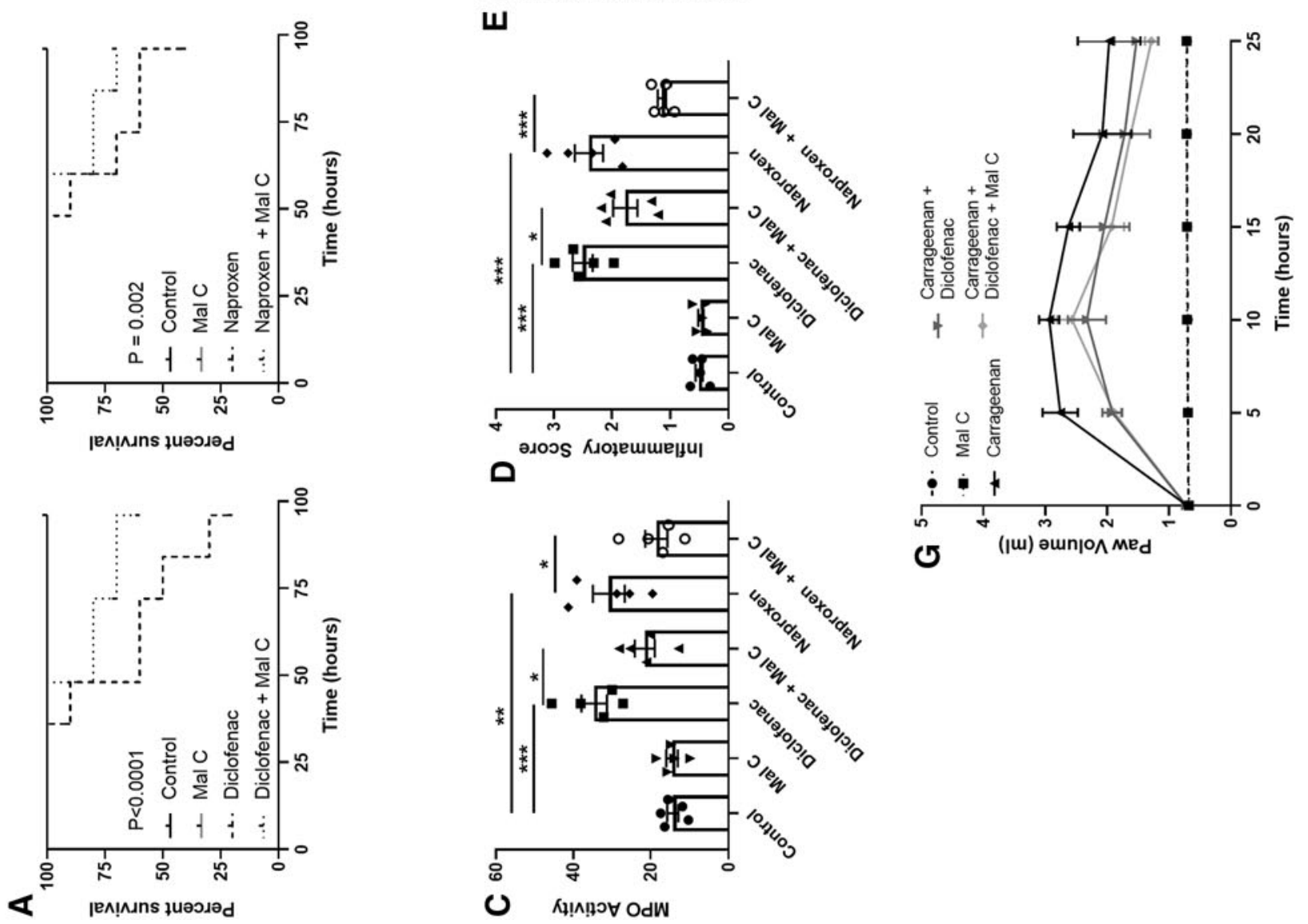

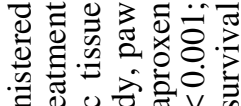

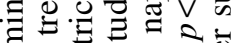

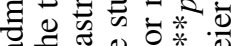

O

o o

일 छ

¿

oi

on o

ठํ.

=

$3 \div 0=2$

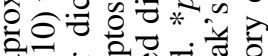

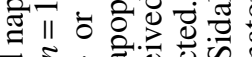

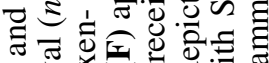

ㅇ. 강 0

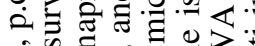

ôn की

일

合交.

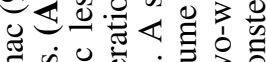

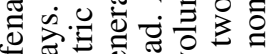

응

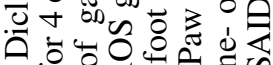

:

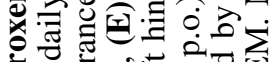

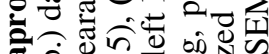

일

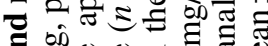

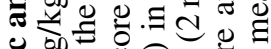

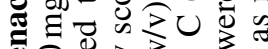

흉을

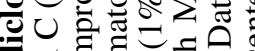

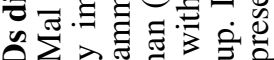

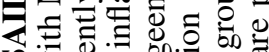

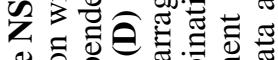

․․ㅇำ

ज行 है है

늘

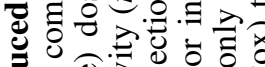

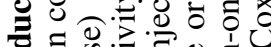

$\Xi . \Xi 00 . \Xi$

n.

㕰

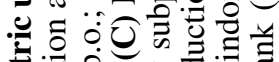

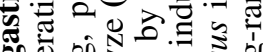

6 은

.

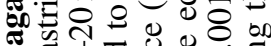

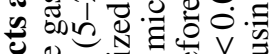

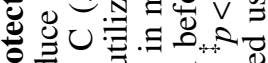

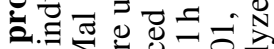

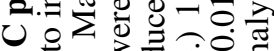

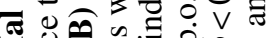

$\sum \cdot$ घ

$\infty$ 응

$\infty$. 0000 .00

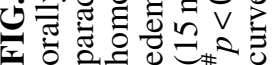




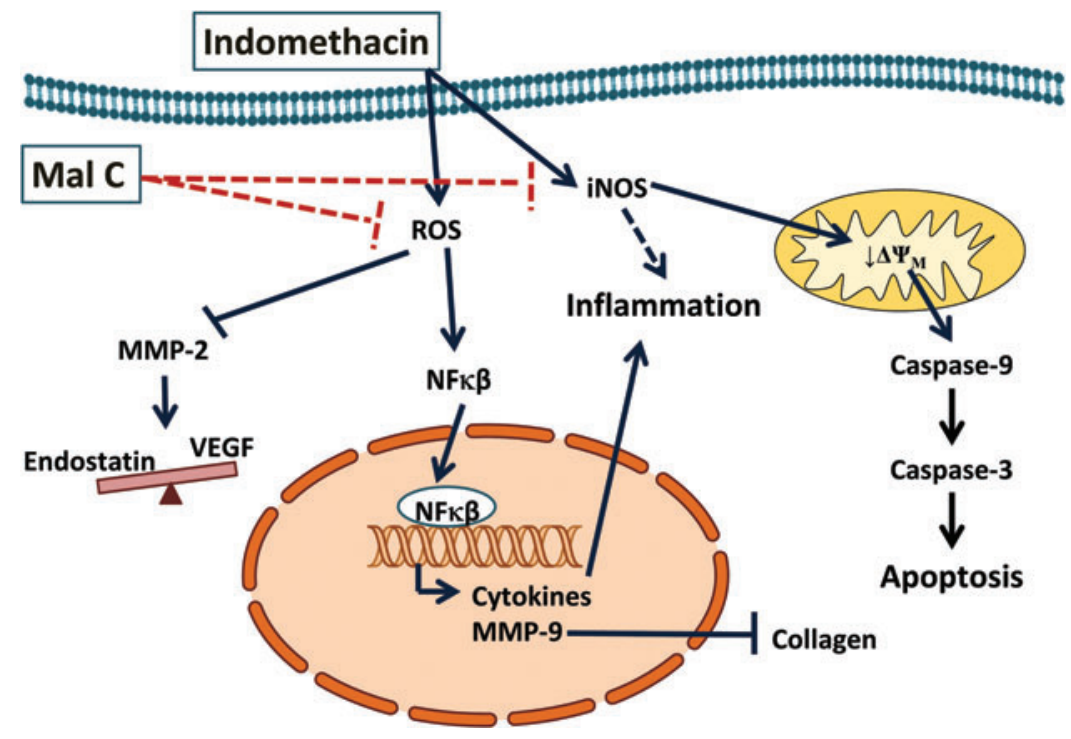

FIG. 9. Mechanistic depiction of the role of Mal $\mathbf{C}$ in indomethacin-induced gastric ulceration. Our central hypothesis is that, by decreasing the production of ROS and RNS (via iNOS), Mal C simultaneously targets multiple parallel pathways involved in various stages of the pathogenesis of NSAID-driven gastropathy. First, Mal C prevents NSAID-dependent mitochondrial dysfunction, caspase activation, and cell death. Next, Mal C decreases inflammation via at least two distinct mechanisms: (i) iNOS and (ii) NF- $\kappa$ B/MMP-9. Finally, Mal $\mathrm{C}$ restores the proangiogenic balance between VEGF and endostatin via actions on MMP-2. RNS, reactive nitrogen species. Color images are available online.

exposed stomachs consistent with previous reports $(25,52)$. These data suggest that iNOS may function parallel to oxidative stress mechanisms, possibly via impacts on the mitochondrial apoptotic signaling cascade (15) in promoting indomethacin-induced gastric injury. Although the exact target(s), whether direct or indirect, of Mal $\mathrm{C}$ in oxidative and nitrative stress signaling remains unknown at this time, the ability of Mal $\mathrm{C}$ to provide gastroprotection heavily relies on decreasing ROS/RNS, a critical nexus upstream of multiple pathogenic cascades contributing to ulceration following NSAID treatment. Although the therapeutic efficacy of antioxidants in treatment of various GI diseases remains controversial (24), the unique effector profile of

Table 1. Pharmacokinetic Parameters for Malabaricone C AdMinistered Orally OR INTRAVENOUSLY

\begin{tabular}{lcc}
\hline Pharmacokinetic parameters & i.v. & \multicolumn{1}{c}{ Oral } \\
\hline$t_{\max }(\mathrm{min})$ & 2.9 & 7.8 \\
$C_{\max }(\mathrm{mg} / \mathrm{L})$ & $2.56 \pm 0.60$ & $0.05 \pm 0.01$ \\
$\mathrm{AUC} C_{0-t}(\mathrm{mg} / \mathrm{mL} / \mathrm{min})$ & $7.91 \pm 1.86$ & $0.7 \pm 0.14$ \\
$\mathrm{CL}(\mathrm{L} / \mathrm{kg} / \mathrm{min})$ & $0.532 \pm 0.15$ & $0.27 \pm 0.13$ \\
$t_{1 / 2}(\mathrm{~min})$ & $4.73 \pm 1.86$ & $14.65 \pm 2.63$
\end{tabular}

Mice $(n=10)$ were given a single Mal C dose intravenously $(10 \mathrm{mg} / \mathrm{kg}$, i.v. $)$ or orally $(200 \mathrm{mg} / \mathrm{kg}$, p.o. $)$, and plasma concentrations of Mal $\mathrm{C}$ determined by high-performance liquid chromatography 5-60 min following drug administration. Concentration values were fitted to a one-compartmental model to determine key pharmacokinetic parameters.

$\mathrm{AUC}_{0-\mathrm{t}}$, area under the curve of a plasma concentration versus time profile; $\mathrm{CL}$, total plasma clearance; $C_{\max }$, maximum concentration; i.v., intravenous; Mal C, malabaricone C; p.o., per os; $t_{\max }$, time to reach $C_{\max } ; \mathrm{t}_{1 / 2}$, elimination half-life.
Mal C suggests that Mal C targets both oxidative and nitrative stress signalings in a tissue- and environment-specific manner increasing its potential utility as a novel therapeutic.

GI side effects are shared across multiple classes of NSAIDs, although generally less common with COX-2 selective drugs such as celecoxib. Indeed, evidence suggests that, despite the dogmatic depiction of COX-1 as a constitutively expressed housekeeper maintaining the gastric mucosa and COX-2 as a mediator of inflammation, inhibition of both enzymes is required for gastric ulceration (60). Although differing in their relative potency, in addition to indomethacin, the non-COX selective prescription NSAID diclofenac and the over-the-counter medication naproxen induced gastric lesions, inflammation, and oxidative stress that could be ameliorated by the addition of Mal C. Similarly, $\mathrm{Mal} \mathrm{C}$ failed to interfere with the anti-inflammatory properties of either drug in the carrageenan-induced paw edema assay. Thus, the beneficial impact of Mal C on NSAIDinduced GI complications may be shared across multiple NSAID classes.

The ability of Mal $\mathrm{C}$ to improve gastric ulceration and inflammation was consistently better than that of omeprazole, the current standard of care in NSAID-induced ulcer treatment and prophylaxis (19). Mal C also proved more efficacious than other antioxidant molecules, including the natural product curcumin, which carries a high risk of adverse side effects derived from promiscuous binding to a number of targets, including cardiac human ether-a-go-gorelated gene channels $(39,63)$. Indeed, Mal $\mathrm{C}$ has a unique capacity to prevent oxidative stress and inflammation while simultaneously promoting angiogenic signaling cascades necessary for ulcer healing, actions not shared by omeprazole, which provided only modest protection against NF- $\kappa \mathrm{B}$ activation, accumulation of inflammatory cytokines, MMP-9 
upregulation, and VEGF depletion at a standard therapeutic dose despite a clear ability to decrease gastric juice acidity. These observations are consistent with a previous report demonstrating that omeprazole has antiapoptotic, antioxidant (7), and proangiogenic (48) actions, but only at high doses.

Indomethacin-mediated gastric ulcers are driven by depletion of protective prostaglandins synthesized by COX enzymes in the gastric mucosa (34), although additional COXindependent mechanisms likely also contribute, including mitochondrial dysfunction and inflammation. Inhibition of COX enzymes is also critical for the anti-inflammatory and analgesic capacity of NSAIDs. Thus, our observation that Mal C was capable of preventing NSAID-dependent COX-1/2 downregulation and $\mathrm{PGE}_{2}$ depletion led to the concern that Mal $\mathrm{C}$ might interfere with the therapeutic efficacy of NSAIDs, negating its utility as an adjunct therapy for NSAIDinduced gastric ulceration. However, using a well-characterized model of acute inflammation, carrageenan-induced paw edema, we observed no impact of Mal $\mathrm{C}$ on the ability of indomethacin, diclofenac, or naproxen to lessen swelling. The lack of significant impacts of Mal $\mathrm{C}$ on inflammatory processes outside the GI tract may derive from weak penetrance of the compound into the circulation following oral administration. Furthermore, Mal C-dependent impacts on serum cytokine levels likely reflect changes originating in the GI tract (46). Indeed, we now show that, at a dose one order of magnitude higher than the maximal efficacious dose of Mal C, levels of drug in the peripheral circulation are detectable but low (submicromolar, $\sim 0.3 \mu M$ ). We conclude that either the impact of Mal C is confined to the site of administration (e.g., the gut) or that the impact of Mal C on COX enzymes fails to interfere with COX inhibition at distant sites (Table 1). Regardless, our observation that Mal C is capable of improving gastric integrity without impacting NSAID efficacy suggests that the underlying mechanism(s) are functionally, temporally, or spatially distinct and, most importantly from a clinical perspective, dissociable.

Further pharmacokinetic profiling will be necessary to conclusively determine the exact site(s) of Mal $\mathrm{C}$ action. Importantly, even at doses much higher $(100-500 \mathrm{mg} / \mathrm{kg}$ ) than those used for this study $(10 \mathrm{mg} / \mathrm{kg})$, Mal $\mathrm{C}$ fails to impact appetite, weight, urine, and fecal output, or liver and kidney histopathology in rodents $(3,4)$. Similarly, chronic dosing has proven safe with no overt toxicities noted (41, 44). While the drug might not be an ideal agent in its present form, the dramatic therapeutic potential indicates that it would serve as a viable lead compound. Recently, a synthesis strategy for Mal C was described (26), which may accelerate the entry of Mal $\mathrm{C}$ into the drug development pipeline.

\section{Materials and Methods}

Animals

Mice experiments were performed at the Department of Pharmaceutical Sciences, Babasaheb Bhimrao Ambedkar University in association with the Geethanjali College of Pharmacy, Hyderabad, India (Ref No: 1648/PO/Re/S/12/ CPCSEA/52). Animals were procured from Biological E. Limited (Azamabad, Hyderabad; Registration \#38/99/ CPCSEA) after obtaining clearance from the Animal Ethics Committee and were handled following International Animal
Ethics Committee Guidelines. Male Swiss albino mice (25$30 \mathrm{~g}, 2-3$ months) were maintained on a balanced laboratory diet as per National Institute of Nutrition, Hyderabad, India, and given tap water ad libitum. Animal housing facilities were kept at $20 \pm 2{ }^{\circ} \mathrm{C}, 65-70 \%$ humidity, and day/night cycle $(12 \mathrm{~h} / 12 \mathrm{~h})$. Animals were group housed 2-5 mice/cage. Unless otherwise noted, drugs were administered to mice via oral gavage (p.o.). As only male animals were used for the studies described herein, the results may not extrapolate to female subjects, and further experimentation will be required to rule out the impacts of genetic sex on endpoints described.

\section{Isolation and purification of Mal C}

Pure Mal C was isolated from the methanol extract of dried fruit rind of $M$. malabarica and fully characterized as reported earlier (42) at the Department of Pharmaceutical Sciences, Babasaheb Bhimrao Ambedkar University. Briefly, dry fruit rinds $(25 \mathrm{~g})$ of $M$. malabarica were ground into powder form and then processed for extraction with methanol ( $50 \mathrm{~mL} \times 5$ days with each solvent, respectively), at room temperature. The supernatants were filtered through a nylon mesh, evaporated at $<40^{\circ} \mathrm{C}$ in vacuo to isolate Mal C. Part of the methanolic extract was subjected to partial fractionation using a silica gel ( $25 \mathrm{~g})$ column, eluting with hexane. This was then subjected to rigorous column chromatography (silica gel, 0-20\% EtOAc/hexane) to isolate Mal C. Purity of the extract was validated via high-performance liquid chromatography (HPLC) and nuclear magnetic resonance analysis (Supplementary Fig. S7).

\section{Plasma concentration measurement of $\mathrm{Mal} C$ in mice}

Eight hours before the Mal $\mathrm{C}$ administration, the animals were deprived of food. Twenty male mice (weighing 23$27 \mathrm{~g}$ ) were divided into two groups: i.v. group (10 mg/kg Mal C, i.v.) and the oral gavage group (200 mg/kg Mal C, p.o.). Twenty-four hours before the Mal $\mathrm{C}$ administration, the animals were subjected to vein and/or artery catheter implantation. These catheters were used for serial blood collection at 5-60 min postdrug dosing.

\section{HPLC analysis of Mal C}

The HPLC system consisted of an Agilent 1200 series Infinity with a $50 \mu \mathrm{L}$ sample loop coupled to UV-Vis detector set to $420 \mathrm{~nm}$ and a computer system for data acquisition. Separation was achieved using a reversed-phase Symmetry C18 column (particle size $5 \mu \mathrm{m}$ ). A mobile phase consisting of methanol, acetonitrile, and 5\% acetic acid (35:50:15, v/v) was used at a flow rate of $1.0 \mathrm{~mL} / \mathrm{min}$.

\section{Indomethacin-induced ulceration}

Ulceration in the mice was induced by a single dose of indomethacin (Sigma, St. Louis, MO; $18 \mathrm{mg} / \mathrm{kg}$ body weight, p.o.) dissolved in distilled water with the vehicle gum acacia (2\%) (Himedia; GRM682). The animals were deprived of food but had free access to tap water $12 \mathrm{~h}$ before ulcer induction. Drugs were prepared as aqueous suspensions in $2 \%$ gum acacia and administered to the mice orally. Mal C (10 mg/kg, once daily, p.o.), omeprazole (3 mg/kg, once daily, p. o.; Sigma), L-NAME (10 mg/kg, once daily, p.o.; Sigma), L-NIL (3 mg/kg, twice daily, p.o.; Sigma), NAC 
( $250 \mathrm{mg} / \mathrm{kg}$, once daily, p.o.; Sigma), thalidomide (200 mg/ $\mathrm{kg}$, twice daily, intraperitoneal [i.p.]; Sigma), or Bay11 ( $5 \mathrm{mg} / \mathrm{kg}$, once daily, i.p.; Sigma) was administered up to the third day postulceration. The dose of the positive control, omeprazole, was taken from a previous report (3). The following experimental groups were used: group I-vehicle control; group II-indomethacin; groups III, IV-indomethacin + Mal C or omeprazole; groups V, VI, VII, VIIIindomethacin + L-NIL, L-NAME, NAC, or thalidomide. Groups I and II were given the daily oral dose of vehicle (gum acacia in distilled water, $0.2 \mathrm{~mL}$ per mice) only. All the biochemical and histological assays were performed on day 3 postindomethacin treatment, at which point we observed peak stomach ulceration. In a separate experiment, the efficacy of Mal C was compared with curcumin $(40 \mathrm{mg} / \mathrm{kg}$, i.p., C7727; Sigma), desferrioxamine ( $800 \mathrm{mg} / \mathrm{kg}$, i.p.; Sigma), and vitamin E $(60 \mathrm{mg} / \mathrm{kg}$, i.p.; Sigma) given at 3 days after indomethacin-induced ulceration.

\section{Standardization of doses of Mal C}

To determine the optimal Mal Cdose, ulcerated mice were given different doses of Mal C $(2,5,10,15$, and $20 \mathrm{mg} / \mathrm{kg}$ body weight, p.o.) once per day up to 7 days. The first dose of Mal $\mathrm{C}$ was given $6 \mathrm{~h}$ after indomethacin administration. Mice were sacrificed on the first, third, fifth, and seventh days and $4 \mathrm{~h}$ after administering the last dose of Mal $\mathrm{C}$. The optimized treatment regimen (dose and time) of Mal $\mathrm{C}$ was determined from the inflammatory scoring as described above.

\section{Assessment of ulceration and healing from histopathology and inflammatory score}

The mice were sacrificed by overdose with thiopental. The stomach from the control and treated groups was removed rapidly, opened along the greater curvature, and completely rinsed in phosphate-buffered saline (PBS) solution. The ulcerated portions of the stomach were sectioned after fixing in $10 \%$ formol saline. After $24 \mathrm{~h}$ of fixation and embedding in paraffin blocks, $10 \mu \mathrm{m}$ sections were prepared, stained with hematoxylin and eosin, and visualized by light microscopy. The inflammation score was assigned as follows: 0 -normal mucosa, 1-minimal inflammatory cells, 2-moderate number of inflammatory cells, and 3large number of inflammatory cells. The sections were also coded to eliminate observer bias. Data are presented as the mean \pm standard error of the mean (SEM) from the review of a minimum of three sections per animal and 5-6 animals per group.

\section{Estimation of MPO activity and mucosal neutrophil counts}

The MPO activity was assayed from the glandular portions of the stomach tissues as previously described with slight modification (55). MPO activity was expressed as $\mathrm{mU} / \mathrm{mg}$ protein. The mucosal neutrophil infiltration was evaluated (14) by counting the neutrophil numbers in the histological slides with same number of fields around the blood vessel and nonblood vessel areas in the mucosa. At least 15 fields were evaluated to yield an average neutrophil number in each sample. The experiments were done by two people, blinded to the treatment groups.

\section{Isolation and primary culture of GECs}

Murine glandular GECs were isolated from 12- to 20-weekold mice and cultured following a published method with some modifications (17). Briefly, we dissected out stomachs from adult mice and thoroughly washed the tissue in chilled PBS. The glandular gastric tissues were then transferred to Hank's balanced salt solution with $20 \mathrm{~m} M$ ethylenediaminetetraaceticacid $\left(\mathrm{Ca}^{2+}, \mathrm{Mg}^{2+}\right.$ free) and collagenase. Tissue suspensions were incubated for $10-15 \mathrm{~min}$ at $37^{\circ} \mathrm{C}$, at which point the epithelium was separated from the mesenchyme carefully with the aid of forceps under aseptic conditions. Next, we transferred the epithelial tissues to Ham's F12 culture medium with required supplementation $(10 \%$ horse serum [Thermo Fisher Scientific; Cat \#16050130], $1 \mathrm{mg} / \mathrm{mL}$ bovine serum albumin [85171; SRL], $100 \mu \mathrm{g} / \mathrm{mL}$ bovine pituitary extract [Thermo Fisher Scientific; Cat \#13028014], $10 \mathrm{ng} / \mathrm{mL}$ EGF [Sigma; Cat \#E5036], $5 \mu \mathrm{g} / \mathrm{mL}$ insulin [Sigma; Cat \#I2643], and $0.5 \mu \mathrm{g} / \mathrm{mL}$ cholera toxin [Cayman Chemicals, Ann Arbor, MI; Cat \#19654]) and dissociated the tissue into small pieces by repeated pipetting. Cells were cultured in the same medium on dishes precoated with collagen in a humidified atmosphere of $5 \% \mathrm{CO}_{2}$ in air at $37^{\circ} \mathrm{C}$. Twenty-four hours postisolation, cells were treated with indomethacin $(30 \mu M)$ for different time points in the presence or absence of Mal C $(10 \mu M)$ and omeprazole $(50 \mu M)$ where indicated. Cells were also pretreated with L-NIL $(50 \mu M)$, NAC $(5 \mathrm{~m} M)$, thalidomide $(10 \mu \mathrm{g} / \mathrm{mL})$, MMP-2 inhibitor I (Santa Cruz Biotechnology, Dallas, TX; $5 \mu M$ ), Bay11-7082 (Sigma; $10 \mu M$ ), DMTU (Sigma; $1 \mathrm{~m} M$ ), Peg-SOD (Sigma; $1000 \mathrm{U} / \mathrm{mL}$ ), and Peg-Cat (Sig$\mathrm{ma} ; 200 \mathrm{U} / \mathrm{mL})$ where indicated.

\section{Preparation of gastric mucosal samples, serum, and GEC lysates for enzyme-linked immunosorbent assays (PGE 2 , NOS, cytokines, VEGF, endostatin, and MMP-9)}

For the $\mathrm{PGE}_{2}$ enzyme-linked immunosorbent assay (ELISA; R \& D Systems, Minneapolis, MN), stomachs were dissected, the corpus excised and weighed $(\sim 100 \mathrm{mg})$, tissue suspended in $10 \mathrm{~m} M$ sodium phosphate buffer, minced finely, and incubated at $37^{\circ} \mathrm{C}$ for $20 \mathrm{~min}$. After centrifugation $(9000 \mathrm{~g})$, the supernatant was extracted for downstream analyses. For additional ELISAs, the glandular part of the stomach tissue was minced $(15 \mathrm{mg})$ and homogenized, or GECs lysed in a lysis buffer $(10 \mathrm{~m} M$ Tris- $\mathrm{HCl} \mathrm{pH} 8.0$, $150 \mathrm{~m} M \mathrm{NaCl}$, and $1 \%$ Triton $\mathrm{X}-100$ ) containing leupeptin $(2 \mu \mathrm{g} / \mathrm{mL})$ and phenylmethylsulfonyl fluoride (PMSF; $0.4 \mu M$ ) after being washed with PBS containing protease inhibitors. Following centrifugation at $15,000 \mathrm{~g}$ for $30 \mathrm{~min}$ at $4^{\circ} \mathrm{C}$, the supernatant was collected. Serum was also isolated from blood extracted via heart puncture and diluted with PBS (1:2). For all ELISAs, absorbance spectrophotometry was carried out at $25^{\circ} \mathrm{C}$ using an ELISA reader (BioTek Instruments, Winooski, VT). Following lysate preparation, ELISAs were carried out following the manufacturer's specifications with no notable deviations. The ELISA for NOS activity in serum and gastric tissue homogenates was from Abcam (Cambridge, United Kingdom). The ELISA kits for the analyses of TNF- $\alpha$, IL- $1 \beta$, IL4 , IL-10, IL-6, and transforming growth factor- $\beta 1$ (TGF- $\beta 1$ ) were obtained from Thermo Fisher Scientific (Waltham, 
MA). The VEGF and MMP-9 ELISA kits were obtained from R\&D Systems, and the endostatin ELISA kit from Chemicon (Temecula, CA).

\section{Arginase assay}

Arginase activity from homogenates of the glandular portion of stomach tissue (isolated as above) was assessed according to a published method (12). One unit of enzyme activity is defined as the amount of enzyme that catalyzes the formation of $1 \mu \mathrm{mol}$ of urea/min.

\section{Total nitrite/nitrate content and NOS activity assay}

Total nitrite/nitrate contents in gastric tissue homogenates were measured according to the method of Miranda et al. (36) and modified by Motawi et al. (37).

\section{MMP-9 activity assays}

The MMP-9 activity in the stomach tissue was detected as per Swarnakar et al. (56), with slight modifications. Proteolysis was detected as a white band against a blue background (negative staining). Enzymatic activity was imaged by Kodak gel doc software (Rochester, NY).

\section{Analysis of p65-DNA binding}

Nuclear extracts from gastric tissue or primary GECs isolated from adult mice were prepared using the Nuclear Extraction Kit (Biovision, Milpitas, CA), and the DNAbinding activity of p65 quantified using the ELISA-based Trans-AM NF- $\kappa$ B p65 kit (Active Motif, Carlsbad, CA) according to the manufacturer's protocol.

\section{Measurement of MTP $\left(\Delta \psi_{m}\right)$}

MTP was measured in GECs as previously described (18). In brief, mitochondria were isolated and incubated with JC-1 (Sigma; $300 \mathrm{nM}$ ) in the dark for $10 \mathrm{~min}$ at $37^{\circ} \mathrm{C}$. The fluorescence was recorded using a spectrofluorometer (excitation, $490 \mathrm{~nm}$; emission, $590 \mathrm{~nm}$ for J-aggregate and $530 \mathrm{~nm}$ for J-monomer).

\section{Measurement of ROS generation and apoptosis}

ROS generation was estimated in the primary GECs using the cell-permeable, oxidation-sensitive probe $\mathrm{CM}-\mathrm{H}$ ${ }_{2}$ DCFDA (Sigma) as described previously (62). $\mathrm{H}_{2} \mathrm{O}_{2}$ generation (Cayman Chemicals) and cell death (Roche, Basel, Switzerland) were measured from cell and tissue lysates prepared as above via ELISA kits. Apoptotic cells were also detected using an annexin V/propidium iodide kit (Sigma) and visualized using fluorescent microscopy. Caspase- 9 and caspase- 3 activity was measured from the cytosolic fraction of gastric mucosal homogenates as well as isolated GEC lysates using commercially available kits (Biovision).

\section{Estimation of oxidative stress biomarkers and gastric juice acidity}

SOD (Sigma), lipid peroxidation (Abcam), and total protein carbonyl (Abcam) activities were assayed from gastric tissue homogenates using ELISA kits as above.
Reduced glutathione activity was measured from gastric tissue homogenates using the method of Ellman (16). The level of gastric juice acidity was determined by titration with $0.01 \mathrm{M} \mathrm{NaOH}$, using phenol red as an indicator (1).

\section{Collagen estimation}

Gastric tissues were dried and hydrolyzed in $6 \mathrm{~N} \mathrm{HCl}$ for $4 \mathrm{~h}$ at $130^{\circ} \mathrm{C}$. Tissues were then processed to estimate the collagen content as described by Sharma et al. (49). Hydroxyproline was detected by the colorimetric assay kit following the manufacturer's protocol (Abcam).

\section{Immunoblotting}

The glandular portion of stomach tissue was minced after being washed with PBS containing protease inhibitors and homogenized in a lysis buffer $(10 \mathrm{~m} M$ Tris- $\mathrm{HCl} \mathrm{pH} 8.0$, $150 \mathrm{mM} \mathrm{NaCl}$, and $1 \%$ Triton X-100) containing leupeptin $(2 \mu \mathrm{g} / \mathrm{mL})$ and PMSF $(0.4 \mu M)$. Lysis of primary murine cultured gastric cells was performed using the same buffer. Following centrifugation at $15,000 \mathrm{~g}$ for $30 \mathrm{~min}$ at $4^{\circ} \mathrm{C}$, the supernatant was collected and the protein concentration measured. Protein samples $(20 \mu \mathrm{g})$ were resolved by $10 \%$ sodium dodecyl sulfate/polyacrylamide gel electrophoresis and transferred to nitrocellulose membrane. The membrane was blocked for $2 \mathrm{~h}$ in Tris buffered saline with Tween 20 buffer and incubated overnight at $4{ }^{\circ} \mathrm{C}$ with appropriate primary antibodies. The membrane was incubated with peroxidase-conjugated secondary antibodies for $1 \mathrm{~h}$. The bands were detected using an enhanced chemiluminescence detection kit and visualized on a ChemiDoc detector (Analytik, Jena, Germany). Densitometric quantification of Western blots was performed utilizing ImageJ software (NIH). Protein expression was normalized to loading controls and expressed relative to control conditions. Antibodies for iNOS (sc-7271), eNOS (sc-37642), COX-1 (sc-19998), COX-2 (sc-19999), VEGF (sc-57496), VEGF receptors Flt-1 (sc-31173) and Flk-1 (sc-6251), MMP-2 (sc-13594), endostatin (sc-32720), and $\beta$-actin (sc-8432) were purchased from Santa Cruz Biotechnology. The MMP9 antibody (AB19016) was from Millipore, and the NF- $\kappa \mathrm{B}$ antibody (\#8242) was from Cell Signaling (Danvers, MA). A table summarizing information on antibodies used is available as Supplementary Table S1. Full, uncropped Western blot images are available in Supplementary Figure S8.

\section{Carrageenan-induced paw edema}

Male Swiss mice from 2 to 3 months old (25-30 g) were divided into groups ( $n=6$ each group) and lightly anesthetized just before the injection. Each group of animals received subplantar administration of $50 \mu \mathrm{L}$ of saline or $50 \mu \mathrm{L}$ of carrageenan $1 \%(\mathrm{w} / \mathrm{v})$ in saline. The paw was marked instantly. The volume was measured using a Vernier caliper, especially for small-volume measurement immediately before and after the injection in different time points. The experimental assessment was performed in a double-blinded manner. The difference in paw volume was measured by subtracting initial paw volume to the paw volume measured at each time point. 


\section{Statistical analyses}

Initial sample size for the study cohorts was determined from a simple power analysis with $\alpha=0.05$ and $\beta=0.9$. Data were analyzed by Student's $t$-test or one- or two-way analysis of variance with Sidak's multiple comparisons test. Normality of the data was evaluated using the Shapiro-Wilk normality test, and the Brown-Forsythe test was used to determine if variances were equivalent across groups. All survival curves (Kaplan-Meier) were evaluated using the log-rank (Mantel-Cox) test. Statistical analyses were performed using Prism software (San Diego, CA). Results were considered significantly different at $p<0.05$. Values are expressed as mean \pm SEM. The results of all statistical tests performed are available in Supplementary Table S2.

\section{Acknowledgments}

We thank Prof. Raja Roy (Director, Centre of Biomedical Research) for the inspiration and continuous support. We also thank Dr. Meenakshi Munshi, Scientist G, Department of Biotechnology (DBT) for all the help. We also thank Dr. Ashok K. Singh, Babasaheb Bhimrao Ambedkar University, and Dr. A.S. Bhaduria, Deen Dayal Upadhyaya Gorakhpur University, for their intellectual help toward preparation of the article.

\section{Author Disclosure Statement}

No competing financial interests exist.

\section{Funding Information}

This work was supported by the Centre of Biomedical Research internal research funds and Ramalingaswami Reentry Fellowship, Department of Biotechnology, India (BT/ RLF/Re-entry/15/2013), to B.M.

\section{Supplementary Material}

Supplementary Figure S1 Supplementary Figure S2 Supplementary Figure S3 Supplementary Figure S4 Supplementary Figure S5 Supplementary Figure S6 Supplementary Figure S7 Supplementary Figure S8 Supplementary Table S1 Supplementary Table S2

\section{References}

1. Abdel-Raheem IT. Gastroprotective effect of rutin against indomethacin-induced ulcers in rats. Basic Clin Pharmacol Toxicol 107: 742-750, 2010.

2. Ardi VC, Kupriyanova TA, Deryugina EI, and Quigley JP. Human neutrophils uniquely release TIMP-free MMP-9 to provide a potent catalytic stimulator of angiogenesis. Proc Natl Acad Sci U S A 104: 20262-20267, 2007.

3. Banerjee D, Bauri AK, Guha RK, Bandyopadhyay SK, and Chattopadhyay S. Healing properties of malabaricone B and malabaricone $\mathrm{C}$, against indomethacin-induced gastric ulceration and mechanism of action. Eur J Pharmacol 578: 300-312, 2008.

4. Banerjee D, Maity B, Bandivdeker AH, Bandyopadhyay SK, and Chattopadhyay S. Angiogenic and cell proliferating action of the natural diarylnonanoids, malabaricone $\mathrm{B}$ and malabaricone $\mathrm{C}$ during healing of indomethacininduced gastric ulceration. Pharm Res 25: 1601-1609, 2008.

5. Beck PL, Xavier R, Lu N, Nanda NN, Dinauer M, Podolsky DK, and Seed B. Mechanisms of NSAID-induced gastrointestinal injury defined using mutant mice. Gastroenterology 119: 699-705, 2000.

6. Bindu S, Mazumder S, Dey S, Pal C, Goyal M, Alam A, Iqbal MS, Sarkar S, Azhar Siddiqui A, Banerjee C, and Bandyopadhyay U. Nonsteroidal anti-inflammatory drug induces proinflammatory damage in gastric mucosa through NF-kappaB activation and neutrophil infiltration: antiinflammatory role of heme oxygenase- 1 against nonsteroidal anti-inflammatory drug. Free Radic Biol Med 65: 456-467, 2013.

7. Biswas K, Bandyopadhyay U, Chattopadhyay I, Varadaraj A, Ali E, and Banerjee RK. A novel antioxidant and antiapoptotic role of omeprazole to block gastric ulcer through scavenging of hydroxyl radical. J Biol Chem 278: 1099311001, 2003.

8. Bradley LM, Douglass MF, Chatterjee D, Akira S, and Baaten BJ. Matrix metalloprotease 9 mediates neutrophil migration into the airways in response to influenza virusinduced toll-like receptor signaling. PLoS Pathog 8: e1002641, 2012.

9. Chairmandurai AR, Kanappa SV, Vadrevu KM, Putcha UK, and Venkatesan V. Recombinant human epidermal growth factor alleviates gastric antral ulcer induced by naproxen: a non-steroidal anti inflammatory drug. Gastroenterol Res 3: 125-133, 2010.

10. Chiu S, Wang T, Belski M, and Abourashed EA. HPLCguided isolation, purification and characterization of phenylpropanoid and phenolic constituents of nutmeg kernel (Myristica fragrans). Nat Prod Commun 11: 483-488, 2016.

11. Conaghan PG. A turbulent decade for NSAIDs: update on current concepts of classification, epidemiology, comparative efficacy, and toxicity. Rheumatol Int 32: 1491-1502, 2012.

12. del Ara RM, Gonzalez-Polo RA, Caro A, del Amo E, Palomo L, Hernandez E, Soler G, and Fuentes JM. Diagnostic performance of arginase activity in colorectal cancer. Clin Exp Med 2: 53-57, 2002.

13. Delclaux C, Delacourt C, D'Ortho MP, Boyer V, Lafuma C, and Harf A. Role of gelatinase B and elastase in human polymorphonuclear neutrophil migration across basement membrane. Am J Respir Cell Mol Biol 14: 288295, 1996.

14. Ding SZ, Lam SK, Yuen ST, Wong BC, Hui WM, Ho J, Guo $\mathrm{X}$, and Cho $\mathrm{CH}$. Prostaglandin, tumor necrosis factor alpha and neutrophils: causative relationship in indomethacininduced stomach injuries. Eur J Pharmacol 348: 257-263, 1998.

15. Dubey M, Nagarkoti S, Awasthi D, Singh AK, Chandra T, Kumaravelu J, Barthwal MK, and Dikshit M. Nitric oxidemediated apoptosis of neutrophils through caspase- 8 and caspase-3-dependent mechanism. Cell Death Dis 7: e2348, 2016.

16. Ellman GL. Tissue sulfhydryl groups. Arch Biochem Biophys 82: 70-77, 1959. 
17. Fukamachi H, Ichinose $M$, Ishihama S, Tsukada S, Yasugi S, Shiokawa K, Furihata C, Yonezawa S, and Miki K. Fetal rat glandular stomach epithelial cells differentiate into surface mucous cells which express cathepsin $E$ in the absence of mesenchymal cells in primary culture. Differentiation 56: 83-89, 1994.

18. Guha M, Kumar S, Choubey V, Maity P, and Bandyopadhyay U. Apoptosis in liver during malaria: role of oxidative stress and implication of mitochondrial pathway. FASEB J 20: 1224-1226, 2006.

19. Gwee KA, Goh V, Lima G, and Setia S. Coprescribing proton-pump inhibitors with nonsteroidal anti-inflammatory drugs: risks versus benefits. J Pain Res 11: 361-374, 2018.

20. Gyenge M, Amagase K, Kunimi S, Matsuoka R, and Takeuchi K. Roles of pro-angiogenic and anti-angiogenic factors as well as matrix metalloproteinases in healing of NSAID-induced small intestinal ulcers in rats. Life Sci 93: 441-447, 2013.

21. Jackson MA, Goodrich JK, Maxan ME, Freedberg DE, Abrams JA, Poole AC, Sutter JL, Welter D, Ley RE, Bell JT, Spector TD, and Steves CJ. Proton pump inhibitors alter the composition of the gut microbiota. Gut 65: 749-756, 2016.

22. Kalyanaraman B, Darley-Usmar V, Davies KJ, Dennery PA, Forman HJ, Grisham MB, Mann GE, Moore K, Roberts $\mathrm{LJ}$, 2nd, and Ischiropoulos $\mathrm{H}$. Measuring reactive oxygen and nitrogen species with fluorescent probes: challenges and limitations. Free Radic Biol Med 52: 1-6, 2012.

23. Kang J, Tae N, Min BS, Choe J, and Lee JH. Malabaricone C suppresses lipopolysaccharide-induced inflammatory responses via inhibiting ROS-mediated Akt/IKK/NF-kappaB signaling in murine macrophages. Int Immunopharmacol 14: 302-310, 2012.

24. Khan I, Samson SE, and Grover AK. Antioxidant supplements and gastrointestinal diseases: a critical appraisal. Med Princ Pract 26: 201-217, 2017.

25. Khattab MM, Gad MZ, and Abdallah D. Protective role of nitric oxide in indomethacin-induced gastric ulceration by a mechanism independent of gastric acid secretion. Pharmacol Res 43: 463-467, 2001.

26. Kundu K and Nayak SK. Total syntheses of malabaricones B and C via a cross-metathesis strategy. J Nat Prod 80: 1776-1782, 2017.

27. Lanas A. Role of nitric oxide in the gastrointestinal tract. Arthritis Res Ther 10 Suppl 2: S4, 2008.

28. Lee S, Jilani SM, Nikolova GV, Carpizo D, and IruelaArispe ML. Processing of VEGF-A by matrix metalloproteinases regulates bioavailability and vascular patterning in tumors. J Cell Biol 169: 681-691, 2005.

29. Liu T, Zhang L, Joo D, and Sun SC. NF-kappaB signaling in inflammation. Signal Transduct Target Ther 2: 17023, 2017.

30. Ma L, Elliott SN, Cirino G, Buret A, Ignarro LJ, and Wallace JL. Platelets modulate gastric ulcer healing: role of endostatin and vascular endothelial growth factor release. Proc Natl Acad Sci U S A 98: 6470-6475, 2001.

31. Maity B, Yadav SK, Patro BS, Tyagi M, Bandyopadhyay SK, and Chattopadhyay S. Molecular mechanism of the anti-inflammatory activity of a natural diarylnonanoid, malabaricone C. Free Radic Biol Med 52: 1680-1691, 2012.

32. Maity P, Bindu S, Dey S, Goyal M, Alam A, Pal C, Mitra $\mathrm{K}$, and Bandyopadhyay U. Indomethacin, a non-steroidal anti-inflammatory drug, develops gastropathy by inducing reactive oxygen species-mediated mitochondrial pathology and associated apoptosis in gastric mucosa: a novel role of mitochondrial aconitase oxidation. J Biol Chem 284: 30583068, 2009.

33. Marlicz W, Loniewski I, Grimes DS, and Quigley EM. Nonsteroidal anti-inflammatory drugs, proton pump inhibitors, and gastrointestinal injury: contrasting interactions in the stomach and small intestine. Mayo Clin Proc 89: 16991709, 2014.

34. Matsui H, Shimokawa O, Kaneko T, Nagano Y, Rai K, and Hyodo I. The pathophysiology of non-steroidal antiinflammatory drug (NSAID)-induced mucosal injuries in stomach and small intestine. J Clin Biochem Nutr 48: 107111, 2011.

35. Melcarne L, Garcia-Iglesias $\mathrm{P}$, and Calvet X. Management of NSAID-associated peptic ulcer disease. Expert Rev Gastroenterol Hepatol 10: 723-733, 2016.

36. Miranda KM, Espey MG, and Wink DA. A rapid, simple spectrophotometric method for simultaneous detection of nitrate and nitrite. Nitric Oxide 5: 62-71, 2001.

37. Motawi TK, Abd Elgawad HM, and Shahin NN. Gastroprotective effect of leptin in indomethacin-induced gastric injury. J Biomed Sci 15: 405-412, 2008.

38. Nagano Y, Matsui H, Muramatsu M, Shimokawa O, Shibahara T, Yanaka A, Nakahara A, Matsuzaki Y, Tanaka N, and Nakamura Y. Rebamipide significantly inhibits indomethacin-induced mitochondrial damage, lipid peroxidation, and apoptosis in gastric epithelial RGM-1 cells. Dig Dis Sci 50 Suppl 1: S76-S83, 2005.

39. Nelson KM, Dahlin JL, Bisson J, Graham J, Pauli GF, and Walters MA. The essential medicinal chemistry of curcumin. J Med Chem 60: 1620-1637, 2017.

40. Opdenakker G, Van den Steen PE, Dubois B, Nelissen I, Van Coillie E, Masure S, Proost P, and Van Damme J. Gelatinase B functions as regulator and effector in leukocyte biology. J Leukoc Biol 69: 851-859, 2001.

41. Othman MA, Yuyama K, Murai Y, Igarashi Y, Mikami D, Sivasothy Y, Awang K, and Monde K. Malabaricone C as natural sphingomyelin synthase inhibitor against dietinduced obesity and its lipid metabolism in mice. ACS Med Chem Lett 10: 1154-1158, 2019.

42. Patro BS, Bauri AK, Mishra S, and Chattopadhyay S. Antioxidant activity of Myristica malabarica extracts and their constituents. J Agric Food Chem 53: 6912-6918, 2005.

43. Rahme E, Joseph L, Kong SX, Watson DJ, and LeLorier J. Cost of prescribed NSAID-related gastrointestinal adverse events in elderly patients. Br J Clin Pharmacol 52: 185192, 2001.

44. Rathee JS, Patro BS, Brown L, and Chattopadhyay S. Mechanism of the anti-hypertensive property of the naturally occurring phenolic, malabaricone $\mathrm{C}$ in DOCA-salt rats. Free Radic Res 50: 111-121, 2016.

45. Scheiman JM. The use of proton pump inhibitors in treating and preventing NSAID-induced mucosal damage. Arthritis Res Ther 15 Suppl 3: S5, 2013.

46. Schirmer M, Smeekens SP, Vlamakis H, Jaeger M, Oosting M, Franzosa EA, Horst RT, Jansen T, Jacobs L, Bonder MJ, Kurilshikov A, Fu J, Joosten LAB, Zhernakova A, Huttenhower C, Wijmenga C, Netea MG, and Xavier RJ. Linking the human gut microbiome to inflammatory cytokine production capacity. Cell 167: 1897, 2016. 
47. Schmassmann A. Mechanisms of ulcer healing and effects of nonsteroidal anti-inflammatory drugs. Am J Med 104: 43S-51S; discussion 79S-80S, 1998.

48. Schmassmann A, Tarnawski A, Peskar BM, Varga L, Flogerzi B, and Halter F. Influence of acid and angiogenesis on kinetics of gastric ulcer healing in rats: interaction with indomethacin. Am J Physiol 268: G276-G285, 1995.

49. Sharma AV, Ganguly K, Paul S, Maulik N, and Swarnakar S. Curcumin heals indomethacin-induced gastric ulceration by stimulation of angiogenesis and restitution of collagen fibers via VEGF and MMP-2 mediated signaling. Antioxid Redox Signal 16: 351-362, 2012.

50. Somasundaram S, Rafi S, Hayllar J, Sigthorsson G, Jacob M, Price AB, Macpherson A, Mahmod T, Scott D, Wrigglesworth JM, and Bjarnason I. Mitochondrial damage: a possible mechanism of the "topical" phase of NSAID induced injury to the rat intestine. Gut 41: 344-353, 1997.

51. Sostres C, Gargallo CJ, and Lanas A. Nonsteroidal antiinflammatory drugs and upper and lower gastrointestinal mucosal damage. Arthritis Res Ther 15 Suppl 3: S3, 2013.

52. Souza MH, Lemos HP, Oliveira RB, and Cunha FQ. Gastric damage and granulocyte infiltration induced by indomethacin in tumour necrosis factor receptor 1 (TNF-R1) or inducible nitric oxide synthase (iNOS) deficient mice. Gut 53: 791-796, 2004.

53. Stadnyk AW, Dollard C, Issekutz TB, and Issekutz AC. Neutrophil migration into indomethacin induced rat small intestinal injury is CD11a/CD18 and CD11b/CD18 codependent. Gut 50: 629-635, 2002.

54. Suzuki H, Nishizawa T, Tsugawa H, Mogami S, and Hibi T. Roles of oxidative stress in stomach disorders. J Clin Biochem Nutr 50: 35-39, 2012.

55. Suzuki K, Ota H, Sasagawa S, Sakatani T, and Fujikura T. Assay method for myeloperoxidase in human polymorphonuclear leukocytes. Anal Biochem 132: 345-352, 1983.

56. Swarnakar S, Ganguly K, Kundu P, Banerjee A, Maity P, and Sharma AV. Curcumin regulates expression and activity of matrix metalloproteinases 9 and 2 during prevention and healing of indomethacin-induced gastric ulcer. $J$ Biol Chem 280: 9409-9415, 2005.

57. Takeuchi K, Tanigami M, Amagase K, Ochi A, Okuda S, and Hatazawa R. Endogenous prostaglandin E2 accelerates healing of indomethacin-induced small intestinal lesions through upregulation of vascular endothelial growth factor expression by activation of EP4 receptors. J Gastroenterol Hepatol 25 Suppl 1: S67-S74, 2010.

58. Tarnawski AS and Jones MK. Inhibition of angiogenesis by NSAIDs: molecular mechanisms and clinical implications. J Mol Med (Berl) 81: 627-636, 2003.

59. Wallace JL, Keenan CM, and Granger DN. Gastric ulceration induced by nonsteroidal anti-inflammatory drugs is a neutrophil-dependent process. Am J Physiol 259: G462G467, 1990.

60. Wallace JL, McKnight W, Reuter BK, and Vergnolle N. NSAID-induced gastric damage in rats: requirement for inhibition of both cyclooxygenase 1 and 2. Gastroenterology 119: 706-714, 2000.

61. Wallace JL, Syer S, Denou E, de Palma G, Vong L, McKnight W, Jury J, Bolla M, Bercik P, Collins SM, Verdu E, and Ongini E. Proton pump inhibitors exacerbate NSAIDinduced small intestinal injury by inducing dysbiosis. Gastroenterology 141: 1314-1322, 1322 e1-e5, 2011.
62. Yang J, Maity B, Huang J, Gao Z, Stewart A, Weiss RM, Anderson ME, and Fisher RA. G-protein inactivator RGS6 mediates myocardial cell apoptosis and cardiomyopathy caused by doxorubicin. Cancer Res 73: 16621667, 2013.

63. Zhang X, Chen Q, Wang Y, Peng W, and Cai H. Effects of curcumin on ion channels and transporters. Front Physiol 5: 94, 2014.

Address correspondence to: Dr. Biswanath Maity

Centre of Biomedical Research Sanjay Gandhi Post-Graduate Institute of Medical Sciences Campus Raebareli Road

Lucknow, Uttar Pradesh 226014

India

E-mail: bmaity28@gmail.com; bmaity@cbmr.res.in

Dr. Sudipta Saha

Department of Pharmaceutical Sciences Babasaheb Bhimrao Ambedkar University Vidya Vihar, Raebareli Road Lucknow, Uttar Pradesh 226025

India

E-mail: sudiptapharm@gmail.com

Date of first submission to ARS Central, March 29, 2019; date of final revised submission, December 5, 2019; date of acceptance, December 8, 2019.

\begin{tabular}{|c|}
\hline 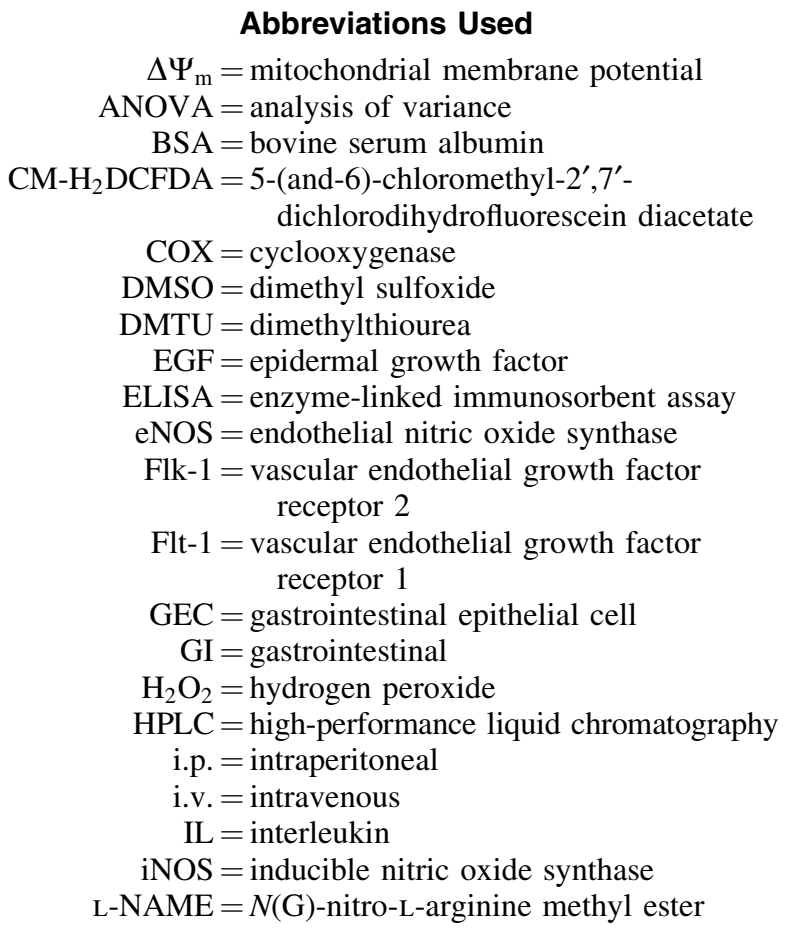 \\
\hline
\end{tabular}




\section{Abbreviations Used (Cont.)}

L-NIL = N6-(1-iminoethyl)-L-lysine, dihydrochloride

Mal $\mathrm{C}=$ malabaricone $\mathrm{C}$

$\mathrm{MMP}=$ matrix metalloproteinase

$\mathrm{MPO}=$ myeloperoxidase

MTP $=$ mitochondrial transmembrane potential

$\mathrm{NAC}=N$-acetylcysteine

$\mathrm{NF}-\kappa \mathrm{B}=$ nuclear factor $\kappa$-light-chain enhancer of activated B cells

$\mathrm{NMR}=$ nuclear magnetic resonance

NOS $=$ nitric oxide synthase

$\mathrm{ns}=$ not significant

$\mathrm{NSAID}=$ nonsteroidal anti-inflammatory drug

$\begin{aligned} \text { p.o. } & =\text { per os } \\ \text { PBS } & =\text { phosphate-buffered saline } \\ \text { Peg-Cat } & =\text { polyethylene glycol-catalase } \\ \text { Peg-SOD } & =\text { polyethylene glycol-superoxide } \\ & \text { dismutase } \\ \mathrm{PGE}_{2} & =\text { prostaglandin } \mathrm{E} 2 \\ \mathrm{PMSF} & =\text { phenylmethylsulfonyl fluoride } \\ \mathrm{PPI} & =\text { proton pump inhibitor } \\ \mathrm{RNS} & =\text { reactive nitrogen species } \\ \mathrm{ROS} & =\text { reactive oxygen species } \\ \mathrm{SEM} & =\text { standard error of the mean } \\ \mathrm{SOD} & =\text { superoxide dismutase } \\ \text { TGF- } \beta 1 & =\text { transforming growth factor- } \beta 1 \\ \mathrm{TNF}-\alpha & =\text { tumor necrosis factor- } \alpha \\ \mathrm{VEGF} & =\text { vascular endothelial growth factor }\end{aligned}$

